\title{
EVALUATION OF SOCIAL AND CULTURAL SUSTAINABILITY IN TYPICAL PUBLIC HOUSE MODELS IN AL AIN, UAE
}

\author{
K. GALAL AHMED \\ Department of Architectural Engineering, United Arab Emirates University, UAE.
}

\begin{abstract}
The Sheikh Zayed Housing Program is the major public housing program in The United Arab Emirates. Through this program hundreds of single family houses for Emirati citizens are being developed every year. The current commitment of the UAE government towards adopting sustainability in the building sector including the housing one initiated a lot of initiatives addressing the issue including this research. The main concern of the research is to go beyond the environmental aspects of sustainability and to address the social and cultural considerations of it in the typical design models of the public houses adopted by The Sheikh Zayed Housing Program. As many public housing projects have been constructed in Al Ain, a city intensively occupied by Emirati citizens, and five housing models prevailed in the city were selected as the scope for this qualitative research with its multi-facets analytical tools including questionnaires and expert analysis of the architectural designs of these models. It has been found that only four out of the eight principles of socio-cultural sustainability in houses have been significantly achieved while other two principles have been found to be partially achieved, and the remaining two principles have been assessed as poorly achieved. Based on these findings, the research has proposed eight design guidelines which are envisaged to help realizing socio-cultural sustainability in the design of the public houses in Al Ain, and in UAE in general.
\end{abstract}

Keywords: Al Ain, cultural, house, public, social, sustainability, UAE.

\section{INTRODUCTION}

Sustainability is both a local and global concern that demands practical, grass root and microclimatic definitions on the one hand, while acknowledging its social and cultural underpinnings on the other hand [1]. Affected by the emergence of widespread concerns over environmental degradation in the 1960s, the concept of environmental 'sustainability' has been the focus for a great deal of work. This included its definition, measurement and the appropriate policies and institutions that can be implemented or promoted in order to achieve it. But more recently both the economic and social dimensions of sustainability have been addressed as additional and interrelated concerns. Thus, sustainability is considered now as a broad multi-focal agenda, where terms such as 'triple bottom line' and 'sustainable development' are being used interchangeably [2]. Currently, it is claimed that the realization of sustainable development should pass through the consideration of, and balance between, environmental, social and economic factors in any development process [3]. Research works stress that these key areas of sustainability should not be separated from one another; rather they should be understood within the holistic framework of sustainable development [4]. Of the three pillars of sustainable development, socio-cultural sustainability is perhaps the least explored within the mainstream development literature [5]. The increasing awareness for building-related sustainability has given birth to many assessment tools, including GB-Tool, BREEAM, LEEDS, CASBEE and HKBEAM which unfortunately certify buildings for their sustainability based on two of the three recognized aspects of sustainability; economy and environment leaving behind social sustainability [4].

This lack of investigation in the domain of social sustainability is in deep contrast with what was mentioned in the Brundtland report of The World Commission on Environment and Development in 1987 which already pointed out that 'perceived needs are socially and culturally determined, and sustainable development requires the promotion of values that encourage consumption standards that are within the bounds of the ecological possible and to which all can reasonably aspire' [6]. 
Chiu [7] argued that for an activity or development to be socially sustainable, it has to keep to specific social relations, customs, structure and value. The influence of social values, norms, and social structure on the continuation or progress of development policies, projects or activities cannot be denied. With its aim of the attainment of social cohesion, integrity, social stability and improvement in the quality of life, social sustainability is people-oriented and refers to maintaining or improving the well being of people in these and future generations.

On the other hand, in his definition for cultural sustainability, Chiu first mentioned the arguments about defining culture by scholars such as Amos Rapoport who argued that culture has two dimensions of elements that determine it, first, the social dimension including kinship, family structure, social network, identity, status and so forth; and second the ideological dimension encompassing values, ideals, images, norms, standards, expectations, rules, and so forth. In another finer definition for culture three major aspects have been highlighted. The first is its esthetic and artistic aspect. This covers fine arts, music, popular culture, performing arts, and so on. The second is the cultivation of mind and spirit which includes knowledge, belief, religion and ideologies. The third is the anthropological perspective meaning the way of life and the social aspect of human behavior. In his attempt to link culture with sustainability Chiu argued that the attributes of culture bear relevance to the sustainability because culture is stored and passed on from one generation to the next and during this process it cumulates, and improves or evolves over time and space, but it may also become extinct. Therefore, culture gives identity to a place over different time periods and thus culture should evolve with socio-economic developments over time, and its evolutionary process should be recognized through conservation of the cultural heritage. But on the other hand, cultural sustainability should not be equated with keeping a culture static. Rather, it refers to sustaining cultural diversity and enabling cultures to evolve.

Chiu believed that there are substantial overlaps between both social and cultural sustainability as they are difficult to separate and are often considered together. However, he added, both the social and cultural sustainability have their respective differences and distinctive areas of concern. Social dimensions may not be tangible and include levels of social cohesion, social stability, social equality, social equity, social conflict, social inclusion and so on. While those of culture, including arts, music, performing arts, literature and religion, may be more tangible [7].

It is argued that although the primary concern of sustainable housing development is to meet the housing needs of the people and not to preserve the environment, the environment at the mean time, should be safeguarded from deteriorating. Furthermore, it is well understood now that sustainable housing should not be merely about meeting basic needs, but should also improve the conditions of both the internal and external living environment [7]. Thus, housing, as a key component of the built environment, plays an important role in all aspects of sustainable development. The sustainability of housing embraces the intertwined environmental, social, cultural and economic aspects [4].

Although research in housing domain normally encompasses both the house and its larger urban context including the neighborhood, the district and the city, but the focus in this research is on the dynamics within the social and cultural spheres of sustainability in the design of public houses in $\mathrm{Al}$ Ain city in UAE. Al Ain is a quite medium-size city inhabited by about 400,000 persons and located in the western region of Abu Dhabi Emirate. It was chosen for undertaking the research investigations because of the accessibility of the required data for the researcher who is based in Al Ain. More importantly, Al Ain has become the preferred living place for many of the UAE citizens due to its more convenient living conditions, especially socially and culturally, if compared to other main cities such as Dubai and Abu Dhabi which are rapidly converting to 'global' cities. The UAE government through its institutions, such as the Sheikh Zayed Housing Program, has been developing single family houses for the Emirati families with no consideration for constructing other patterns 
of public housing such as apartment units. The public housing authorities have justified that by the belief that this type of houses is the most desirable type for the Emirati people. For Al Ain, there are many public houses that were developed by Al Ain Municipality in regions such as Neima, Mazyad and Al Maqam. These houses are generously subsidized by the state government with exceptionally low pay-off rates on long-term installments.

The main objective of the research is twofolds. First is investigating the current considerations for applying socio-cultural sustainability measures in the design of these public houses. Second, and based on the first one, is to propose design guidelines that can help achieving more socially and culturally sustainable design for this type of houses. The research is therefore a qualitative research that employed multiple research tools to probe, in-depth, the tackled issues. In order to establish a conceptual framework for the evaluation process, two methods were implemented. First is a literature review for the recent debate about the 'global' concepts and indicators of social and cultural sustainability in houses. Second is refinement of these concepts and indicators to be more locally orientated by the help of the Emirati citizens themselves through a number of focus group sessions conducted with some of them at the UAE University in Al Ain. This 'glocalized' conceptual framework, which lists the socio-cultural sustainability principles, their indicators and their measurable variables for public houses in $\mathrm{Al}$ Ain, was then used in the professional analysis of the architectural designs of five professionally designed and widely built public house models in Al Ain. Meanwhile, this conceptual framework was used in the face-to-face structured interviews with a sample of 60 Emirati families living in the same selected housing prototypes. In order to minimize the bias resulting from the possibility of interviewing only male members of the Emirati families, due to cultural barriers, the investigator recruited and trained some female students at the UAE University who had more chance to undertake interviews with female members of the selected sample. As a result, 28 out of the 60 interviews were with female representatives of the Emirati families. The ages of the interviewed residents ranged between 22 and 64years and the number of occupants in each household were between 4 and 19 occupants where the mean number of them was about 10 occupants. Most of the interviewed families have from 2 to 3 servants at their houses including a male driver and female maids. The majority of the heads of the interviewed households are employees in the public sector including Al Ain Municipality, Abu Dhabi police and UAE armed forces.

\section{ESTABLISHING A CONCEPTUAL FRAMEWORK FOR STUDYING SOCIO-CULTURAL SUSTAINABILITY OF PUBLIC HOUSES IN UAE}

Social sustainability, according to Barnett and Buys [8], includes the features of the house that are considered to lower the risks of injury, improve safety and security, and enhance livability and family life. But the question here is how to establish appropriate indicators to evaluate these features. One generic definition of sustainability indicators is that they are 'bellwether tests of sustainability and reflect on something basic and fundamental to the long-term economic, social or environmental health of a community over generations' [9]. But Mohammad and Amato [4] claimed that assessment of social sustainability for buildings is left out of the tools mainly due to the absence of an established consensus that identifies the relevant social sustainability indicators and also the relative weighting between each of the indicators. They added that the currently developed indicators which attempt to capture the social aspect of sustainable development have been frequently described as inadequate. Despite this difficulty, and in an attempt to define the social and cultural sustainability principles and their indicators for this research, as presented in the following section, the relevant literature about the indicators of social and cultural sustainability was reviewed and then 'localized' through in-depth discussions in focus group sessions as mentioned earlier. 
2.1 Principles and indicators of social and cultural sustainability in houses: a global perspective

The SMART house project [8] provided a good evidence for the achievement of some social and cultural sustainability principles such as the 'responsiveness to the users' needs' and the 'quality of life'. In the project it has been found that spaciousness and ease of access contributed to improved family life. Indoor and outdoor spaces were used for entertaining purposes while smaller and cozier indoor spaces were available for sitting quietly. The interior color scheme and the timber blinds were products that residents would not tire of and this would reduce replacement costs. On the other hand, the residents of the project reported that their well-being was elevated due to the increased comfort provided via good airflow, appropriate natural lighting and easy movement due to the open design of the house [8].

For 'safety', as another important socio-cultural sustainability principle in houses, and in findings from a social study in the 'Sustainable Queensland's Research House' in Australia, residents reported their satisfaction and improved feelings of safety when living in the spacious, airy and secure home [10]. 'Security' and 'privacy' are claimed also as important principles of the socially sustainable house design. A secure house is defined as the one that minimizes the opportunity for crime and maximizes safety of occupants. A large number of reported break-ins usually take place during the day when people are at work. Even if the monetary value of goods stolen is low, house break-in is a devastating crime as victims can feel that their privacy and personal space have been violated by strangers [11]. Some design features in the SMART House project [8] contributed to providing security and privacy for the family. These included strong and easy to clean screens which allowed for good visibility, sensor lights, house alarm, frosted doors and high bathroom windows. Furthermore, residents have had an unobstructed view of the main street and the backyard. Multiple barriers have been placed around the house as to deter criminals trying to enter the house. The garden in this house has been designed to eliminate hiding places for intruders and the plants in the front garden have been kept low.

'Accessibility' is considered one of the most important principles of a socially sustainable house. Fletcher [11] argued that there is a need to redefine social sustainability in order to integrate universal/accessible design. It is claimed that an accessible house is one which its occupants and visitors can enter and move inside easily and comfortably. Accessibility depends essentially on the ability of people and what is accessible for one person may not be accessible for someone else. Accessibility features are particularly important to older people, people with disabilities and children. So, incorporating accessibility measures into house design for each of these groups will allow for easier access and movement for all, now and in the future. Many accessibility issues relate to the original design of the house, so it may be difficult to make changes (for example to widen door widths) [11].

Some measures for realizing 'Universal Design' (UD) in the SMART House Project [8] for residents in wheelchairs, blind residents and little children included: open plan, a flat access to the house, a garage close to the kitchen with a flat access as well, nonslip tiles and a flat access to the shower. In this regard, Fletcher [11] stated seven design requirements of the Fair Housing Accessibility (FHA) including: accessible primary building entrance on an accessible route, accessible and usable public and common use areas, accessible primary entrance and common use area doors, useable secondary doors for persons in wheelchairs, accessible route into and through covered dwelling unit, light switches, electrical outlets, thermostats and other environmental controls in accessible locations, reinforced walls for grab bars, useable kitchens and bathrooms designed for persons in wheelchairs. For single family houses, similar to the case of Al Ain, he recommended one zero-step entrance and that all main floor doors, including bathrooms to be with at least $82 \mathrm{~cm}$ of clear passage space. In addition, he recommended that at least a half bath, preferably a full bath, should be located on the main floor of the house. 
2.2 'Glocalizing' the social and cultural sustainability principles and indicators in public house design in Al Ain

Given the socio-cultural and geographical diversities of human settlements it is almost impossible to provide comprehensive universal standards for social and cultural sustainability principles and indicators. Rather, it is best to leave communities to decide on their own internal and shared qualitative and quantitative social and cultural sustainability indicators rather than defining 'sustainable standards' [7]. Two main focus groups, one formed of 12 Emirati male residents and the second was formed of 10 Emirati female residents, were the main adopted method for discussing the previously addressed 'global' principles with local residents. All the members of both focus groups are living in public houses in Al Ain and they are mainly public sector employees, academic and non-academic staff as well as senior students from the University. The work in these two focus groups had significantly enriched and 'localized' the principles and indicators, originally derived from literature review, thus made them closer to the UAE locality. For example, in these focus groups, the issue of design accessibility has been asserted as it was revealed that the age structure of the UAE citizens, according to the estimations of consensus (2007 estimation), reveals that a considerable number are elderly who need special attention in house design. The age structure is as follows: $0-14$ years: 20.6\% (male 467,931/female 447,045), 15-64 years: 78.5\% (male 2,558,029/female 932,617), 65 years and over: $0.9 \%$ (male 24,914/female 13,475) [note: $73.9 \%$ of the population in the $15-64$ age group is non-national. They are expatriates and their residency in UAE is dependent on their work there] [12]. Also, more emphasis was given to issues such as social cohesion, privacy with servants, outsiders and visitors. For Emirati society visitors or guests are subsumed into two distinctive categories which are reflected significantly in the design of the house itself mainly for the purpose of privacy. Male guests are the male friends of the male members of the family and the family's male relatives. As part of the inherent cultural tradition of the Gulf region in general and for UAE in specific male guests are usually strictly separated from the main internal familial activity zones in the house and thus have their own allocated distinctive activity zones as will be detailed later. Female guests mainly the relatives and friends of the female members of the family are usually received in the main living halls inside the house. According to Emirati cultural traditions maids and 'female' servants who usually come from south Asia from countries such as India, Indonesia, Bangladesh and Philippine are usually allocated separate bedrooms with toilets attached to the main kitchen. Also, if there is a driver he usually has his own bedroom with its toilet built besides the outer house fence and next to the garage.

Other important principles were addressed and discussed in the focus groups sessions including, local customs especially those pertaining to cooking and eating behavior, individual preferences, preservation of the Emirati design heritage, users' participation and the ability for change. So, finally and based on both the above literature review and the outcomes of the focus group sessions, eight principles for social and cultural sustainability in houses in UAE have been identified as follows: responsiveness to social needs, responsive to cultural values, quality of life, adaptability, safety, security, participation, and accessibility (inclusive/universal design). In addition, some relevant indicators with their measurable variables were then tailored for each of these principles as shown in Table 1 [13].

\section{SELECTED DESIGN MODELS OF PUBLIC HOUSES IN AL AIN}

Among the designs of the public single-family houses in Al Ain, five design models were selected for the purpose of conducting the socio-cultural sustainability analysis in this research. These models were selected because they were widely built in Al Ain compared with other ones [12]. They were 
Table 1: The 'glocally' determined principles, indicators and variables of socio-cultural sustainability in houses in UAE [13].

\begin{tabular}{|c|c|c|}
\hline Principles & Indicators & Variables \\
\hline \multirow[t]{7}{*}{$\begin{array}{l}\text { Responsiveness to } \\
\text { social needs }\end{array}$} & $\begin{array}{l}\text { Needed functional } \\
\text { spaces }\end{array}$ & $\begin{array}{l}\text { Suitable number of rooms per occupant } \\
\text { (overcrowding rate). }\end{array}$ \\
\hline & & $\begin{array}{l}\text { Suitable service facilities (toilets, stores, } \\
\text { parking, etc). }\end{array}$ \\
\hline & & Suitable areas for the functional spaces. \\
\hline & & Suitable functional spatial organization (zoning). \\
\hline & & Need for a balcony or terrace. \\
\hline & & Need for a garden. \\
\hline & & Preferred number of floors. \\
\hline \multirow[t]{8}{*}{$\begin{array}{l}\text { Responsiveness to } \\
\text { cultural values }\end{array}$} & $\begin{array}{l}\text { Increased social } \\
\text { cohesion and integrity } \\
\text { among family members. }\end{array}$ & $\begin{array}{l}\text { Relationship among spaces (degree of integration } \\
\text { and segregation, visibility, permeability, } \\
\text { sequencing of spaces). }\end{array}$ \\
\hline & Privacy (with outsiders, & Isolation of servants' zone. \\
\hline & $\begin{array}{l}\text { with servants, with } \\
\text { visitors). }\end{array}$ & $\begin{array}{l}\text { Relationship between family zone and male } \\
\text { visitors zone. }\end{array}$ \\
\hline & & $\begin{array}{l}\text { Orientation of the house and locations of } \\
\text { fenestrations in relation to surrounding houses } \\
\text { and streets. }\end{array}$ \\
\hline & & Entrances (Residents-Visitors). \\
\hline & $\begin{array}{l}\text { Customs (of cooking and } \\
\text { eating behavior). }\end{array}$ & $\begin{array}{l}\text { The location of the main kitchen and the dining } \\
\text { halls. }\end{array}$ \\
\hline & $\begin{array}{l}\text { Continuation of the } \\
\text { expression of folk art } \\
\text { and vernacular } \\
\text { architecture. }\end{array}$ & $\begin{array}{l}\text { Manifestation of collective memory of UAE } \\
\text { people both internally and externally through, } \\
\text { for example, architectural motives in the house } \\
\text { design (facades, details, ornaments, etc). }\end{array}$ \\
\hline & $\begin{array}{l}\text { Preservation of } \\
\text { functional house } \\
\text { design heritage. }\end{array}$ & $\begin{array}{l}\text { Functions and their distribution that are derived } \\
\text { from heritage designs and need to be preserved } \\
\text { in contemporary live. }\end{array}$ \\
\hline \multirow[t]{5}{*}{ Quality of life } & $\begin{array}{l}\text { Healthy indoor } \\
\text { environment (clean } \\
\text { air, water and soil). }\end{array}$ & $\begin{array}{l}\text { Building orientation in relation to the north } \\
\text { direction and sun path (providing natural } \\
\text { ventilation and day-lighting). }\end{array}$ \\
\hline & & $\begin{array}{l}\text { Treatment of noise and air pollution from } \\
\text { surroundings (roads, etc). }\end{array}$ \\
\hline & & $\begin{array}{l}\text { Fittings resisting insects (windows and doors } \\
\text { screens). }\end{array}$ \\
\hline & Good sense of place. & $\begin{array}{l}\text { Ease of movement inside the house (open plan } \\
\text { design, when possible). }\end{array}$ \\
\hline & & $\begin{array}{l}\text { Provision of good views to green areas (gardens) } \\
\text { in the outer courts of the house plot. }\end{array}$ \\
\hline
\end{tabular}




\section{Table 1: Continued}

\begin{tabular}{|c|c|c|}
\hline \multirow[t]{2}{*}{ Adaptability } & $\begin{array}{l}\text { Responsiveness to } \\
\text { individual preferences } \\
\text { concerning functions } \\
\text { and areas of inhabitable } \\
\text { spaces. }\end{array}$ & $\begin{array}{l}\text { Design allows for redistribution of spaces } \\
\text { functions/areas. }\end{array}$ \\
\hline & $\begin{array}{l}\text { Ability for changing } \\
\text { functions/areas of } \\
\text { inhabitable spaces. }\end{array}$ & $\begin{array}{l}\text { Design allows for change in functions/areas of the } \\
\text { internal/external spaces of the house over time. } \\
\text { Design allows for adding more floors/functional } \\
\text { spaces. }\end{array}$ \\
\hline Safety & Protection from hazards. & $\begin{array}{l}\text { Means of fire resistance in design (smoke detector } \\
\text { and alarm in each space). } \\
\text { Anti slippery floorings. } \\
\text { Means of escape in case of emergency. }\end{array}$ \\
\hline Security & Protection from crimes. & $\begin{array}{l}\text { Means of security in design details (fences, suit- } \\
\text { able building materials, lockers, alarms, lighting } \\
\text { sensors, etc). } \\
\text { Relative position (control) for each room in the } \\
\text { plan. } \\
\text { Degree of visibility among internal/external } \\
\text { spaces. }\end{array}$ \\
\hline Participation & $\begin{array}{l}\text { Taking part in } \\
\text { decision-making. }\end{array}$ & $\begin{array}{l}\text { Participation in the selection of the house site and } \\
\text { its plot/built-up area. } \\
\text { Participation in the design of the house. } \\
\text { Participation in the decision of constructing } \\
\text { alternatives. } \\
\text { Participation in the construction of the house. }\end{array}$ \\
\hline \multirow[t]{2}{*}{$\begin{array}{l}\text { Accessibility } \\
\text { (inclusive/universal } \\
\text { design) }\end{array}$} & $\begin{array}{l}\text { Appropriate measures } \\
\text { for elderly inhabitants. }\end{array}$ & $\begin{array}{l}\text { Accessible main plot/house entrances (flat access). } \\
\text { Suitable means for vertical circulation. } \\
\text { Level threshold to each room. }\end{array}$ \\
\hline & $\begin{array}{l}\text { Appropriate measures } \\
\text { for handicapped and } \\
\text { children inhabitants. }\end{array}$ & $\begin{array}{l}\text { Main entrance and common use area doors are } \\
\text { accessible. Other doors must be useable by } \\
\text { persons in wheelchairs. } \\
\text { Light switches, electrical outlets, thermostats and } \\
\text { other environmental control devices in accessible } \\
\text { locations. } \\
\text { Kitchens and bathrooms are designed to be } \\
\text { useable by persons in wheelchairs. } \\
\text { Suitable width and access for car parking space(s). }\end{array}$ \\
\hline
\end{tabular}

named 'Types A, B, C, D and E' just for the purpose of identification in this research. The selected design models actually share many of the design characteristics with each other but with some diversity in forms, functions and areas. These housing prototypes were built mostly during the late1980s until 2004. The average area of the house plot reached about 2025 sq. $\mathrm{m}$ and was usually fenced by a 
reinforced concrete and masonry fence with one main entrance in addition to a car entrance. The built-up area of the house prototype ranged from about 360 sq. $\mathrm{m}$ up to $430 \mathrm{sq}$. $\mathrm{m}$. This area can be, and actually has been in several cases, expanded but after the approval, and under the supervision, of Al Ain Municipality. Type 'A' house model consists of two separated buildings (Fig. 1).

The front one is one floor building containing the male guests' related activities including a majlis hall (sitting hall), a dining hall, a toilet and hand-wash basins. Attached to this building, from its back side, is the service activity wing which encompasses the main kitchen, a store room, the maid's bedroom with a toilet and an electricity room. The second building is built away from the main front gate of the plot and contains the family activities zone on two floors. In the ground floor there is a family living hall, two bedrooms, a bathroom, a kitchenette and hand-wash basins. The first floor contains two bedrooms with a bathroom and a master bedroom (Fig. 1). This prototype was usually built on a $45 \mathrm{~m} \times 45 \mathrm{~m}$ plot with a total built-up area of $431 \mathrm{sq}$. $\mathrm{m}$. The model was designed by an international firm; Hyder Consulting. Through the ' 1810 Houses' public housing project on 10 sites in Al Ain, the construction of the houses of this house model started in 2002 where the first completed houses were handed over to the client in the summer of 2003 [12].

About one thousand houses of Type 'B' house model were constructed in Al Ain. This house model is a two-story block building containing all family, male guests and service activities.

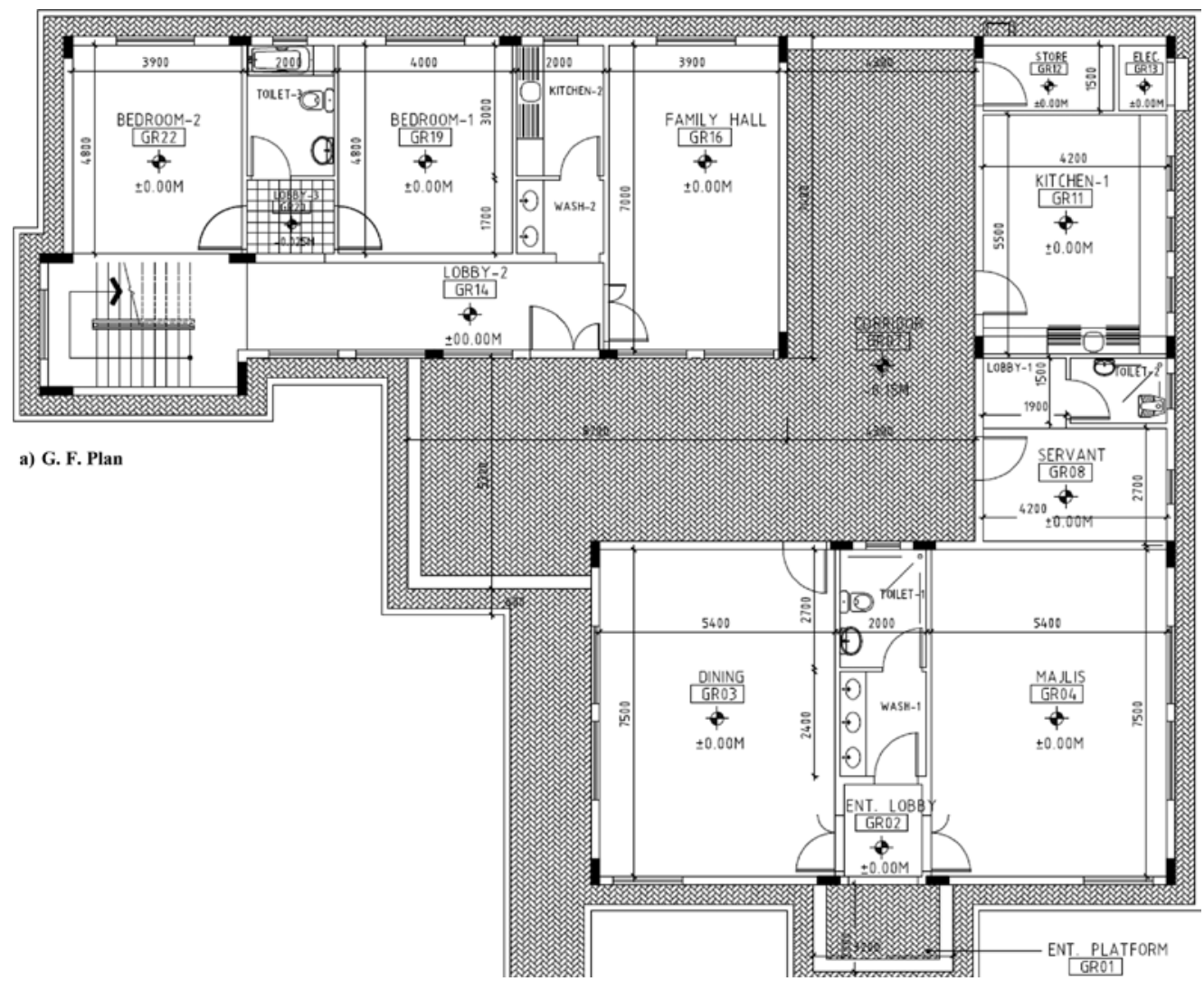

Figure 1: Type "A" house model ([12] and the author) (Continued). 


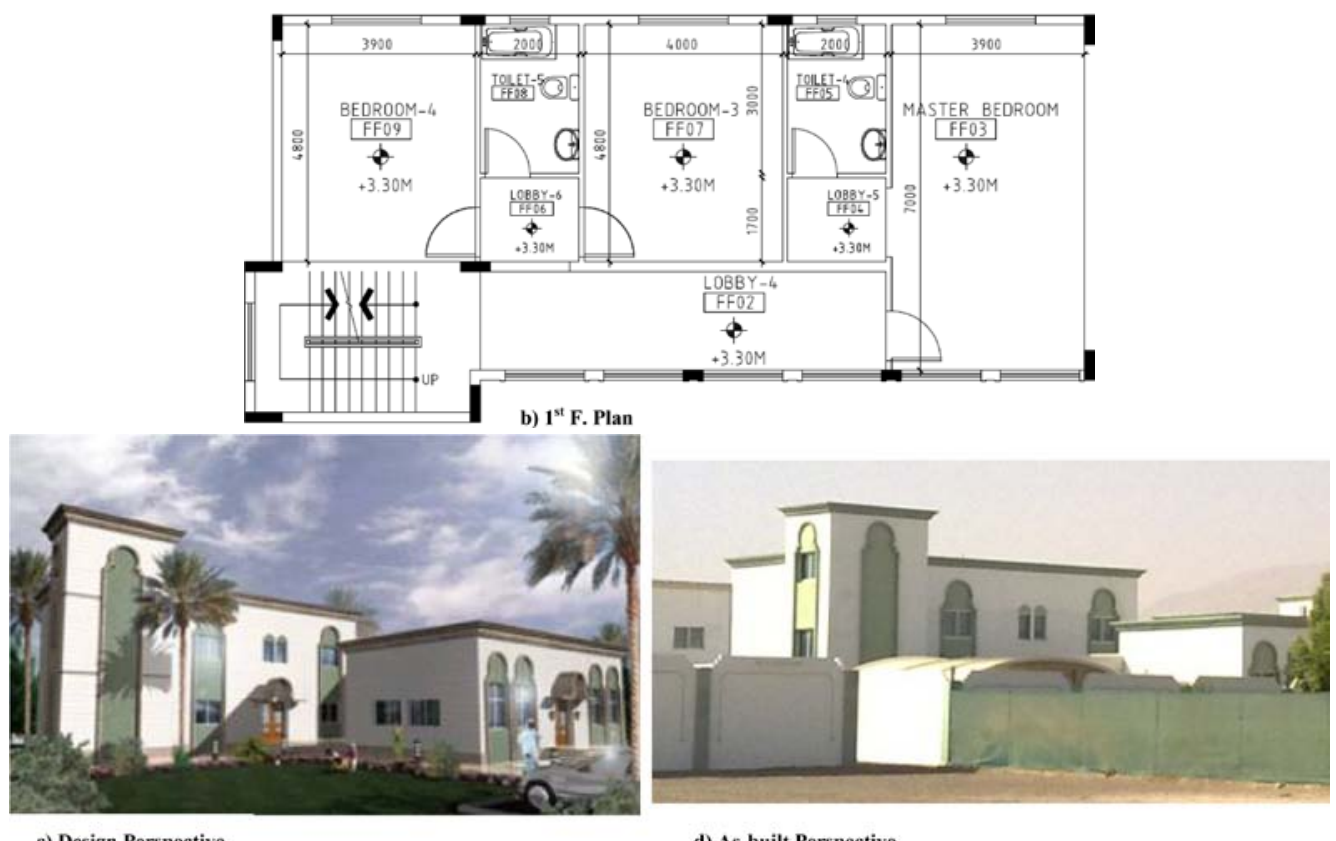

c) Design Perspective

d) As-built Perspective

Figure 1: (Continued).

The house was usually built on a plot measuring approximately $45 \mathrm{~m} \times 45 \mathrm{~m}$ (Fig. 2). The ground floor consists of a main entrance lobby leading to the male guests' zone containing a majlis hall, a dining hall, hand-wash basins and a toilet. The entrance lobby also leads to the family activities area containing a family living hall, a toilet and one bedroom with a toilet. Close to the family zone is the service zone. The service zone consists of the main kitchen, a store, the maid's bedroom with a toilet and an electricity room. The first floor contains four bedrooms, two bathrooms and one master bedroom (Fig. 2). The total built-up area of this model is about 495 sq. m [12].

Type ' $\mathrm{C}$ ' consists of three separate one-story buildings on a plot measuring about $24 \mathrm{~m} \times 33.5 \mathrm{~m}$ (Fig. 3). The main building is allocated for the family activities including a family living hall, four bedrooms, two bathrooms and one master bedroom. The male guests' building is attached to the plot fence with a separate entrance and contains a majlis hall, a dining hall, hand-wash basins and a toilet. The third building is the service building which occupies a rear corner in the plot and encompasses the main kitchen, a store and a maid's bedroom with a toilet (Fig. 3). The total built-up area of this model is about 405 sq. $\mathrm{m}$.

Similar to Type 'C', Type 'D' house model consists of three separated blocks including a twostory building allocated for family activities; one story male guests' building and one story service building (Fig. 4). The plot of this model usually measured about $45 \mathrm{~m} \times 45 \mathrm{~m}$. The family block contains in the ground floor a family majlis hall, a dining hall, hand-wash basins, a toilet and a guest bedroom with a toilet. The first floor of this building contains one master bedroom, two bedrooms, a bathroom and hand-wash basins. The lewan (a semi-closed lobby) is a traditional design item that appeared in both the ground and the first floors of the family activities building and the male guests one (Fig. 4). 

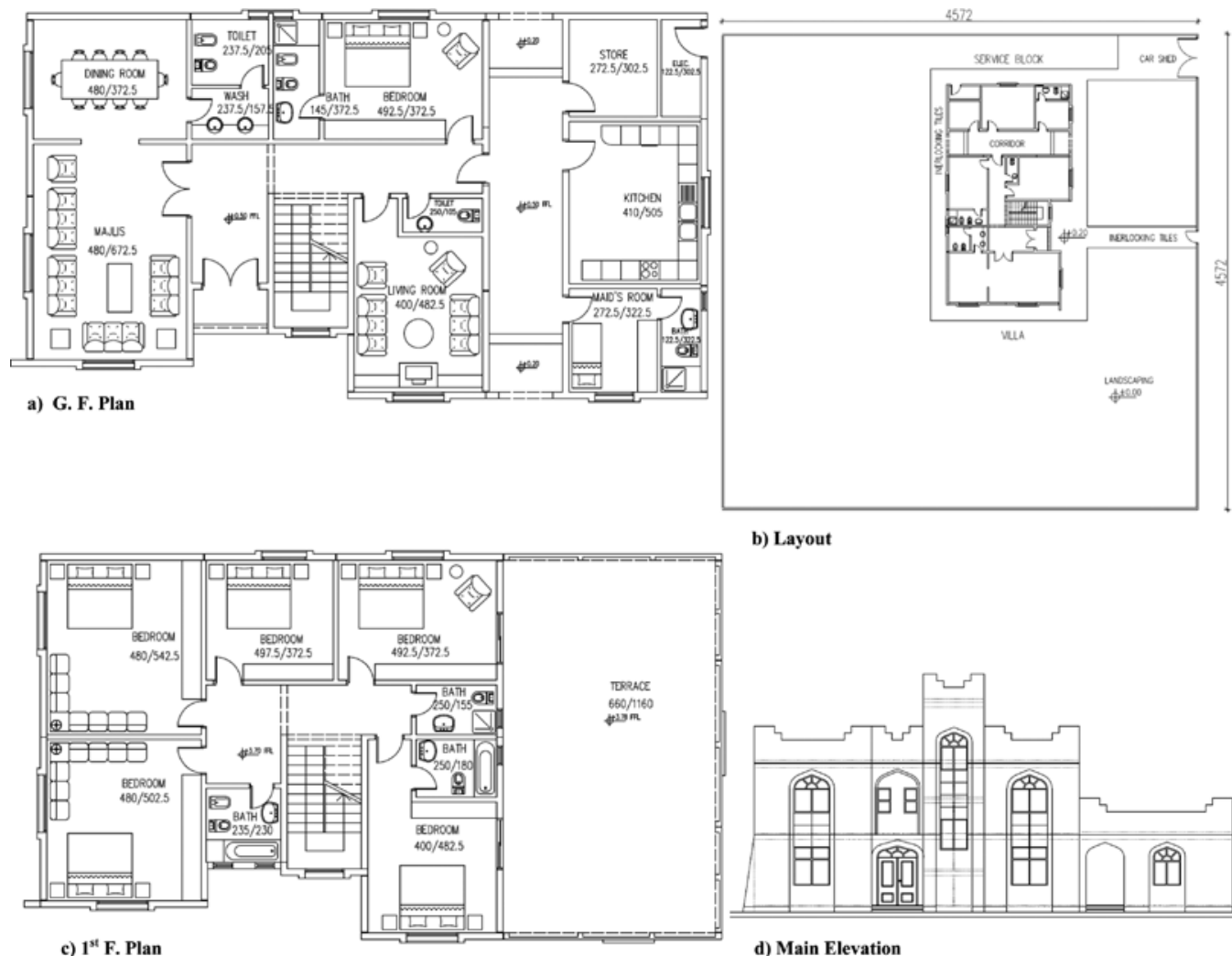

b) Layout

Figure 2: Type 'B' house model [12].

The second block contains the male guests' activities including a majlis hall, a dining hall, handwash basins and a toilet. The total built-up area is about $490 \mathrm{sq} . \mathrm{m}$. This model is distinguished with the presence of double front fences where the front fence is shorter than the rear one with a garden encapsulated between them (Fig. 4).

Type 'E' (Fig. 5) is actually an extended version of the house model Type 'A' (Fig. 1). It is built on $45 \mathrm{~m} \times 45 \mathrm{~m}$ plots with a built-up area equals about $498 \mathrm{sq}$. $\mathrm{m}$. Compared to Type 'A', the ground floor has one extra bedroom and a larger family hall. The first floor contains three bedrooms, two bathrooms, one master bedroom and a small terrace. The design for this extension is usually undertaken by a private consultant office and should be approved first by the Municipality. All the design and construction expenses of this extension are provided by the owner.

The following section discusses to what extent has each of the social and cultural sustainability principles been achieved. This was fulfilled through the evaluation of the relevant indicators of each principle and their measurable variables as shown previously in Table 1. As mentioned earlier, this evaluation process depended on the two adopted research tools, namely, the design analysis and the face-to-face structured interviews with a sample of 60 Emirati families. The evaluation was based on the following qualitative scale expressing the degree of the achievement of each variable, its indicator and finally its principle.

Achieved Largely Achieved
Partially Achieved
Poorly Achieved
Not Achieved 


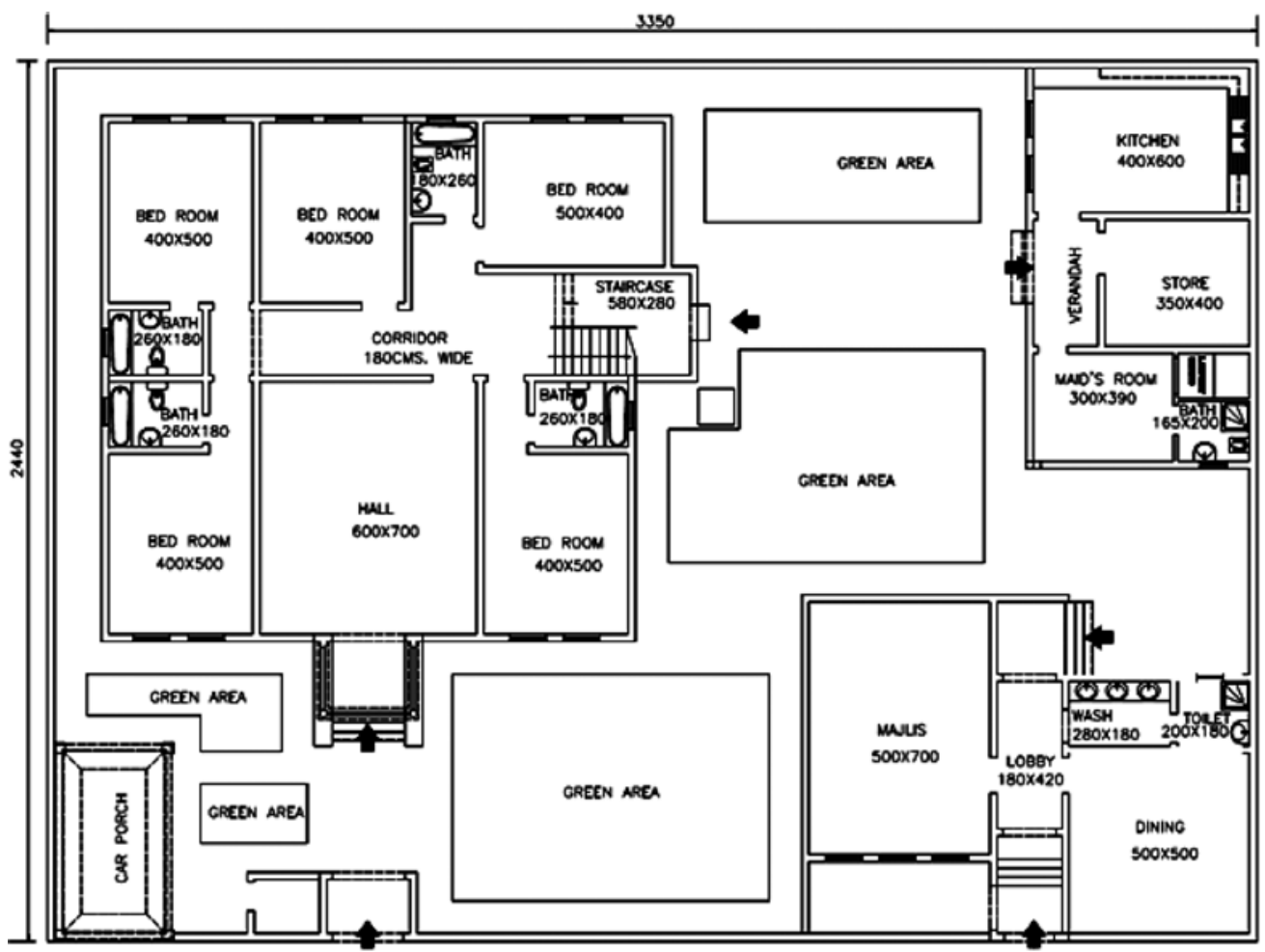

a) G. F. Plan

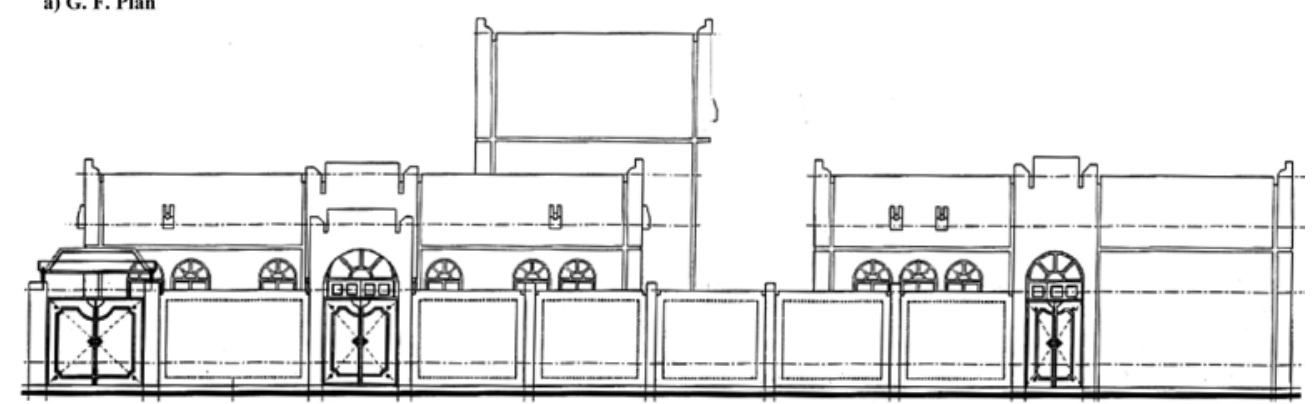

b) Main Elevation

Figure 3: Type 'C' house model [12].

\section{QUALITATIVE EVALUATION OF THE SOCIO-CULTURAL SUSTAINABILITY PRINCIPLES IN PUBLIC HOUSES IN AL AIN}

\subsection{Responsiveness to social needs}

The first investigated principle was the 'Responsiveness to social needs' of the inhabitants. Satisfying 'the needed functional spaces' was the selected indicator for this principle. Seven variables (Table 1) were tailored to help assessing this indicator and hence evaluate its principle. For the first variable, 'the 
suitable number of rooms' it was found that this number ranges between 4 ( 3 and a master bedroom) to 7 (6 and a master bedroom) in the five housing models (Figs 1-5). Actually the case of the 7 rooms (Type E) came as a result of an expansion of the original Type 'A'. The average number of the Emirati household is 9 persons, so the average overcrowding rate is about 1.8 person/room. In their responses to this issue almost half of the interviewed families (53.3\%) were satisfied with the number of rooms they have in their houses while $41.7 \%$ of them found it less than their needs (Table 2).

Actually many of the interviewed families $(58.3 \%)$ managed to increase the number of rooms in their houses to reach up to 10 rooms and even more. The design of the housing models and the sufficient plot areas allowed for incremental increase in response to the need for more rooms. So it can be argued, even indirectly, that the design models proved to be considerably successful in satisfying

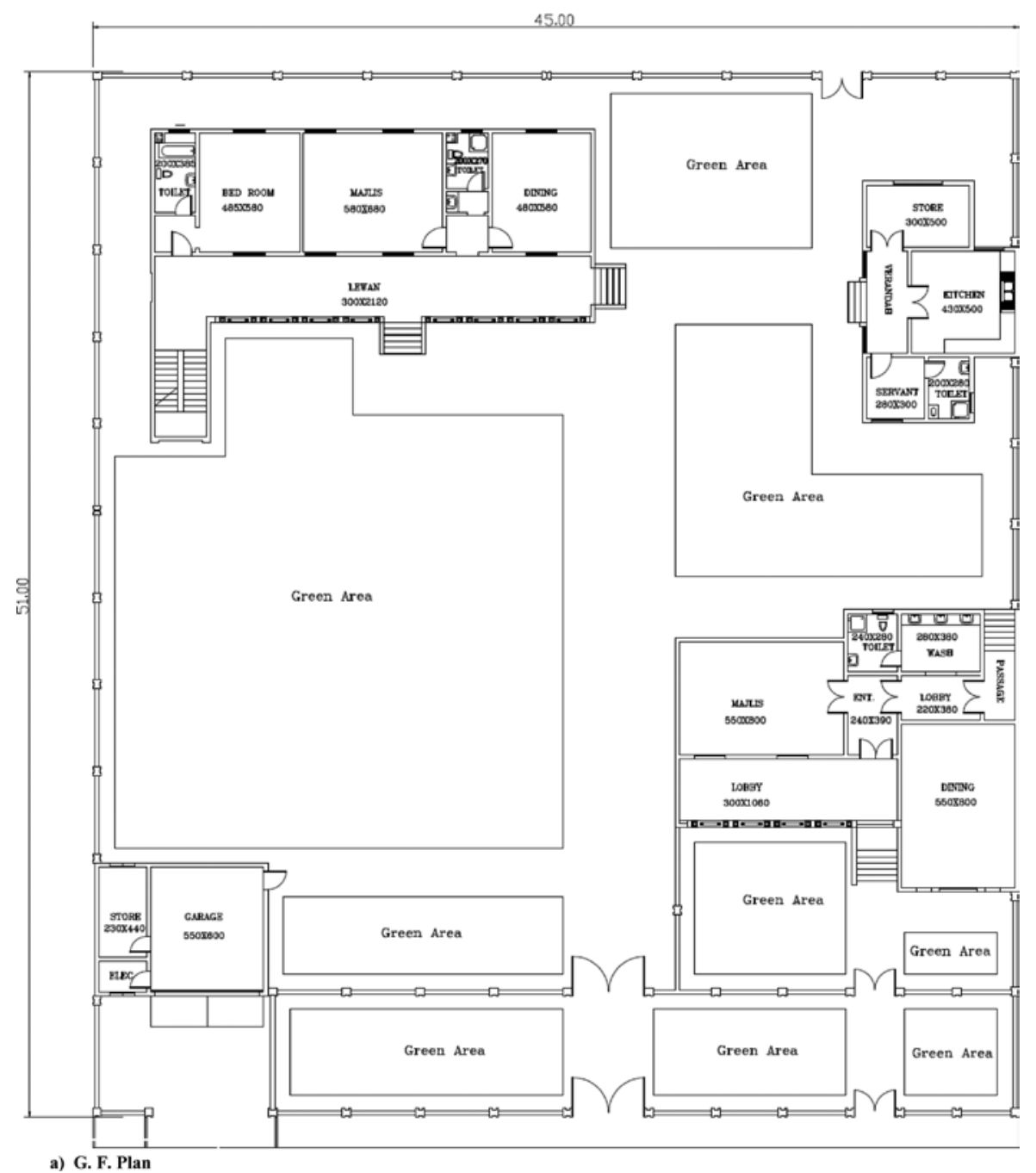

Figure 4: Type 'D' house model ([12] and the author) (Continued). 


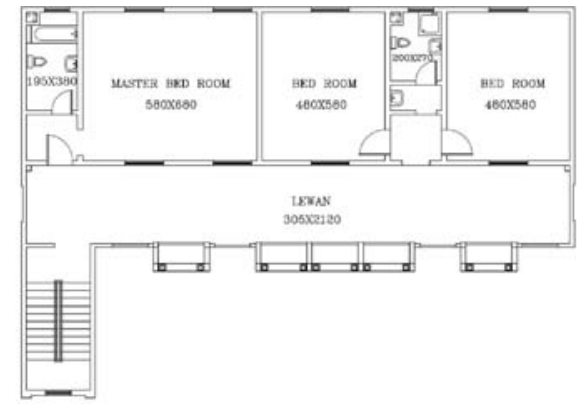

b) $1^{\text {st }}$ F. Plan

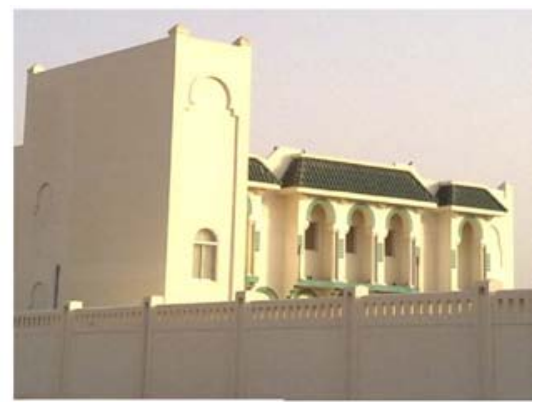

c) Main Block Elevation

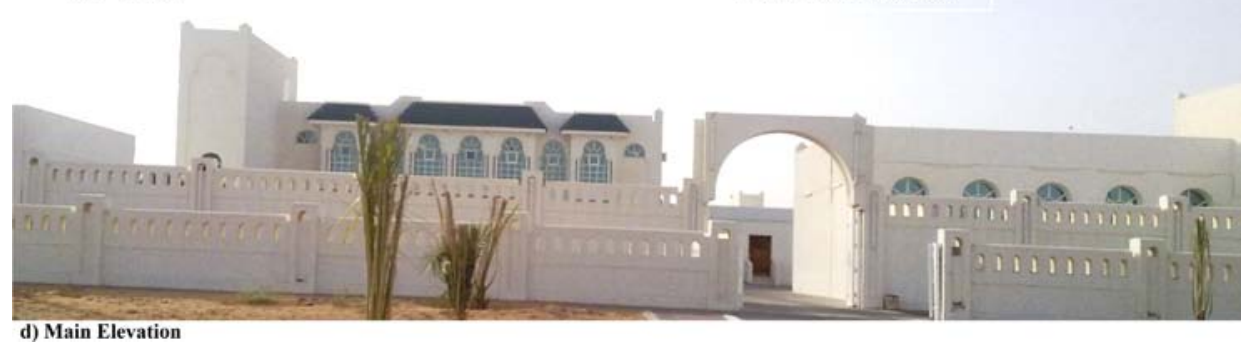

Figure 4: (Continued).

this functional need. On the other hand and by reviewing the design models (Figs 1-5) it can be easily assumed that there are sufficient service facilities including kitchens, bathrooms, servants' rooms, stores and garages. Only $28.3 \%$ of the interviewed families expressed their dissatisfaction with the sufficiency of the number of service facilities in their houses (Table 2). Thus, the design models are considerably providing the needed service facilities for the occupants.

The third investigated variable was the 'suitable areas for the functional spaces' in the house model. These areas, through the design analysis, proved to be generally suitable (Table 3). Still there are some significant variations especially in both Type 'B' which has the least areas for family and guests functional spaces and Type ' $E$ ', as an extended version of Type ' $A$ ', which has larger spaces particularly noticed in the family hall and the master bedroom.

The areas of these functional spaces were considered suitable for $60 \%$ of the interviewed families. Meanwhile, a considerable percentage of them (40\%) thought that these areas are not suitable (Table 2). This can be understood in light of the actual family size of the respondents as $40 \%$ of the interviewed families have 11 persons or more. This, no doubt, necessitates more areas for the house functional spaces. Therefore, it might be argued here that the design models have partially provided suitable areas for functional spaces especially for the majlis and family living halls.

The fourth investigated variable was the 'suitable functional spatial organization (zoning)'. The design analysis showed that Types A, C, D and E are having the same functional spatial organization distinguished with physical separation between the three distinctive activity zones: the family zone, the male guests zone and the service zone. Even the only house model that has one building mass [Type B] has some sort of internal separation, through corridors, between these distinctive activities (Fig. 2). It seems that this spatial organization matches, to a large extent, the social values of the Emirati families. The administered questionnaire revealed that the majority of the interviewed families $(75 \%)$ preferred to have the main kitchen of their houses outside the house. This goes in harmony with a societal tradition to have the kitchen away from living spaces and daily activities 

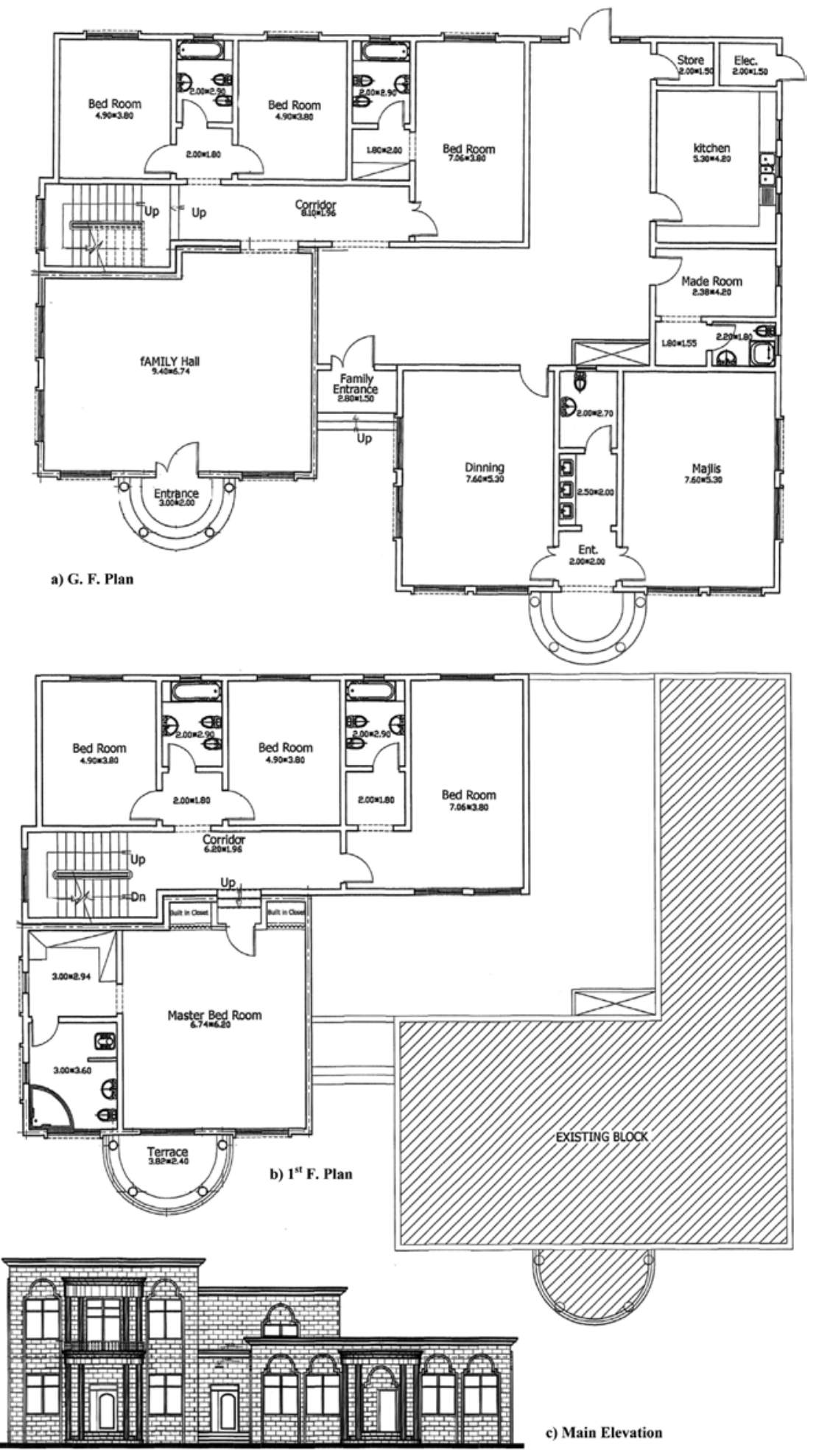

Figure 5: Type 'E' house model [Source: Al Hosn Consultant Office, Al Ain]. 
areas inside the house. Meanwhile, the majority of the interviewed families (66.7\%) preferred to have the servants' rooms isolated outside the house. Still a considerable minority (33.3\%) preferred to have the servants' rooms inside the house. As an explanation, this preference would make it easier for family members to have direct contact with the servants. In conclusion, the majority of the interviewed families $(88.3 \%)$ were either totally satisfied $(23.3 \%)$ or partially satisfied $(65 \%)$ with the distribution of the functional spaces of their houses (Table 2). This indicates that the design has succeeded, even partially, to satisfy the social needs relevant to the distribution of functional spaces.

For other house elements such as balconies and terraces which have no reference in Emirati architectural heritage, the design of the housing models have, in general, neglected them with some few exceptions when the roof of a part of the house is designed to be used as a terrace for some part of the first floor of the house such as the case of Type 'A' (Fig. 1). The majority of the interviewed

Table 2: Results of the interviewees' responses to the variables (questions) of the indicators of the first principle.

\begin{tabular}{|c|c|c|}
\hline Variable (Questions) & Frequency & Percent $(\%)$ \\
\hline \multicolumn{3}{|l|}{ Suitability of no. of rooms } \\
\hline Suitable for household & 32 & 53.3 \\
\hline Exceeds the need of household & 3 & 5 \\
\hline Less than the need of household & 25 & 41.7 \\
\hline \multicolumn{3}{|c|}{$\begin{array}{l}\text { Suitability of no. of service facilities [bathrooms, } \\
\text { servants rooms, stors] }\end{array}$} \\
\hline Suitable for household & 40 & 66.7 \\
\hline Exceeds the need for household & 3 & 5 \\
\hline Less Than the need of household & 17 & 28.3 \\
\hline \multicolumn{3}{|c|}{ Suitability of areas of bedrooms, halls and service facilities } \\
\hline Suitable for the household & 36 & 60 \\
\hline Less than the need of household & 24 & 40 \\
\hline \multicolumn{3}{|l|}{ The location of the kitchen } \\
\hline Inside the house & 20 & 33.3 \\
\hline Outside the house & 40 & 66.7 \\
\hline \multicolumn{3}{|c|}{ Preference for the location of the kitchen } \\
\hline Inside the house & 15 & 25 \\
\hline Outside the house & 45 & 75 \\
\hline \multicolumn{3}{|l|}{ Location of servants' rooms } \\
\hline Inside the house & 25 & 41.7 \\
\hline Outside the house & 35 & 58.3 \\
\hline \multicolumn{3}{|c|}{ Preference of servants' rooms location } \\
\hline Inside the house & 20 & 33.3 \\
\hline Outside the house & 40 & 66.7 \\
\hline \multicolumn{3}{|l|}{ Existence of terraces and balconies } \\
\hline Yes & 15 & 25 \\
\hline No & 45 & 75 \\
\hline
\end{tabular}


Table 2: Continued

\begin{tabular}{lcc}
\hline $\begin{array}{l}\text { Preference of the existence of terraces and balconies } \\
\text { Important }\end{array}$ & 25 & 41.7 \\
Not Important & 35 & 58.3 \\
Existence of house garden & & \\
Yes & 47 & 78.3 \\
No & 13 & 21.7 \\
Preference of the existence of house garden & & \\
Essential & 25 & 51.7 \\
Preferred & 35 & 58.3 \\
Openion about suitable no. of house floors & & 15 \\
One floor & 9 & 75 \\
Two floors & 45 & 10 \\
Three floors & 6 & \\
\hline
\end{tabular}

Table 3: Areas $\left(\mathrm{m}^{2}\right)$ of the main functional spaces in each of the five public house models.

\begin{tabular}{lccccc}
\hline House Model & Family hall & $\begin{array}{c}\text { Male guests } \\
\text { majlis }\end{array}$ & $\begin{array}{c}\text { Male guests } \\
\text { dining }\end{array}$ & $\begin{array}{c}\text { Master } \\
\text { bedroom }\end{array}$ & $\begin{array}{c}\text { Bedrooms } \\
\text { (average) }\end{array}$ \\
\hline Type A & 27 & 40.5 & 40.5 & 31 & 19 \\
Type B & 19.5 & 32 & 18 & 19 & 20.5 \\
Type C & 42 & 35 & 25 & 25 & 22.5 \\
Type D & 40 & 44 & 44 & 42.5 & 29.5 \\
Type E & 68 & 40 & 40 & 50 & 24.5 \\
\hline
\end{tabular}

families (58.33\%) thought that these elements are not important. Still $41.67 \%$ of them believed that balconies and terraces are important elements in their houses.

The UAE government usually delivers the finished house without plantation where the residents can convert it into a paved space or green areas. The majority of the interviewed families $(78.3 \%)$ mentioned that they have house gardens. This is affirmed by their opinion that the presence of gardens in their houses is either essential $(41.67 \%)$ or at least preferred $(58.33 \%)$. None of them mentioned that it is not necessary (Table 2). In addition, the majority of the interviewed families $(75 \%)$ preferred to have two-story houses. This goes in harmony with most of the design models (except Type C). Based on the above analysis it can be concluded that the first investigated principle, the 'Responsiveness to social needs', has been found to be 'Largely Achieved' (Fig. 6).

\subsection{Responsiveness to cultural values}

Five indicators were selected to measure the second principle of socio-cultural sustainability in the investigated houses models: the 'responsiveness to cultural values'. These five indicators are: social cohesion and integrity among family members, privacy (with outsiders, with servants and with visitors), customs (of cooking and eating behavior), continuation of folk art and traditional architecture and 


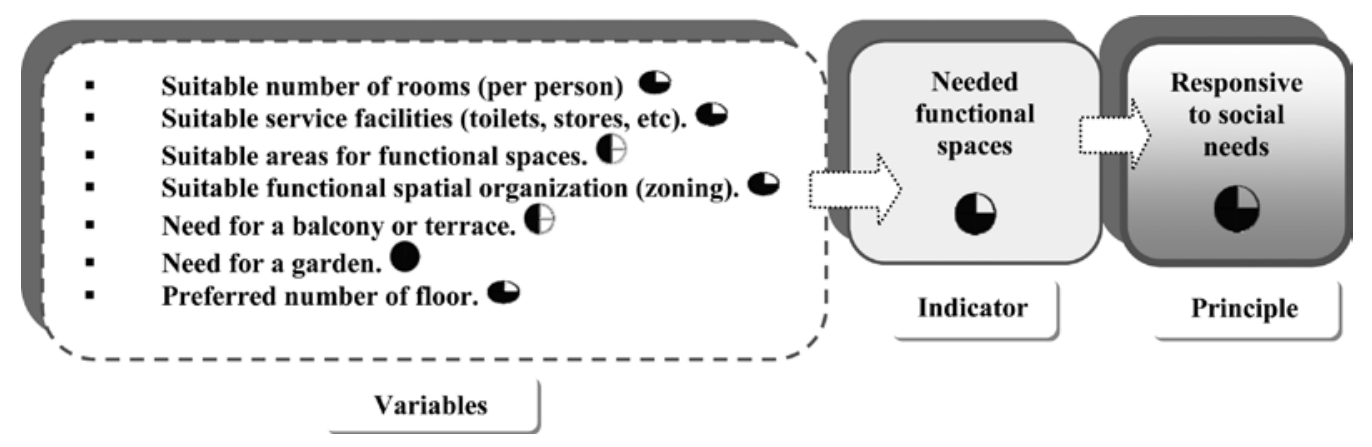

Figure 6: Evaluation of the first principle, 'Responsiveness to social needs'.

preservation of the functional design heritage of the Emirati house. For each indicator, a number of variables have been proposed as shown in Table 1.

The design analysis revealed that Types A, C and D house models have the most integrated functional spaces among the five studied models due to the linear organization of spaces on a controlling lobby in Types A and C or a lewan in Type D. Type E lost part of the original integration of spaces due to the change in the location of the family entrance, if compared with Type A. The family zone in Type B had the least integrated spaces due its compactness with both male guests and service zones. In the questionnaire and when the respondents were asked about whether the organization of the functional spaces of their houses makes the family members see each other frequently, the positive response was high where $83.3 \%$ of them agreed on that (Table 4). This indicated that the house design works in harmony with encouraging social cohesion among family members within the family activities zone.

In terms of privacy, the second indicator of the second principle, and in order to provide privacy from outsiders, high opaque fences surrounding the whole house plot were used (Figs 1, 3 and 4). It was also found that the fragmentation of the three main zones to three distinctive buildings in the house plot in all Types, except Type 'B', has significantly achieved the required degree of privacy of family members with both the servants and male guests but with higher degree of privacy from male guests' zone especially in Type $\mathrm{C}$ where the entrance to this zone comes from outside the plot through a separate remote entrance in the plot fence (Fig. 3). On the other hand, the privacy in Type ' $\mathrm{B}$ ' was less significantly achieved as it was partially realized through some separating corridors and doors only (Fig. 2). Additionally, separated external entrances for both family zones and male guests' zones were found in all the five analyzed Types, except Type 'B', which has only one external entrance.

On the other hand, the majority of the interviewed families $(73.3 \%)$ believed that the design and the orientation of their houses provided sufficient privacy from outsiders (Table 4). Also, the majority of them confirmed the success of the design in providing privacy on both the levels of the male guests and on the level of the servants ( $73.3 \%$ and $71.1 \%$, respectively). Finally, the majority of the interviewed families (75\%) thought that the number of entrances in their houses helped them to have privacy (Table 4). These results illustrated that the design models have considerably managed to provide privacy on various levels to the residents whether from outsiders, male guests and servants.

For the third indicator; 'the customs of cooking and eating behavior', it was found, as mentioned earlier, that the main kitchen is always separated from both the family activity zone and the male 
Table 4: Results of the interviewees' responses to the variables (questions) of the indicators of the second principle.

\begin{tabular}{|c|c|c|}
\hline Variable (Questions) & Frequency & Percent $(\%)$ \\
\hline \multicolumn{3}{|l|}{ Distribution of rooms and halls } \\
\hline Suitable & 14 & 23.3 \\
\hline Suitable to some extent & 39 & 65 \\
\hline Not suitable & 7 & 11.7 \\
\hline \multicolumn{3}{|l|}{ Distribution of house rooms and halls } \\
\hline Enables household to see each other frequently & 50 & 83.3 \\
\hline Makes it rare for household to see each other & 10 & 16.7 \\
\hline \multicolumn{3}{|l|}{ Privacy from outsiders } \\
\hline House design provides enough privacy from outsiders & 44 & 73.3 \\
\hline House design does not provide enough privacy from outsiders & 16 & 26.7 \\
\hline \multicolumn{3}{|l|}{ Privacy from visitors } \\
\hline House design provides enough privacy from visitors & 44 & 73.3 \\
\hline House design does not provide enough privacy from visitors & 16 & 26.7 \\
\hline \multicolumn{3}{|l|}{ Privacy from servants and drivers } \\
\hline House design provides enough privacy from servants and drivers & 43 & 71.1 \\
\hline $\begin{array}{l}\text { House design does not provide enough privacy from servants and } \\
\text { drivers }\end{array}$ & 17 & 28.3 \\
\hline \multicolumn{3}{|l|}{ Suitability of no. of entrances } \\
\hline No. of entrances is adequate for household and visitors & 45 & 75 \\
\hline No. of entrances is exceeding the need for household and visitors & 2 & 3.3 \\
\hline No. of entrances is less than needed for household and visitors & 13 & 21.7 \\
\hline \multicolumn{3}{|l|}{ Actual similarity with design of traditional emirati house } \\
\hline The house assimilate traditional Emirati house in many facets & 18 & 30 \\
\hline The house assimilate traditional Emirati house in some aspects & 37 & 61.7 \\
\hline The house does not assimilate traditional Emirati house & 5 & 8.3 \\
\hline \multicolumn{3}{|l|}{ Opinion about similarity with design of traditional emirati house } \\
\hline The house should assimilate traditional Emirati house & 13 & 21.7 \\
\hline $\begin{array}{l}\text { The house should assimilate traditional Emirati house in some } \\
\text { continuous aspects }\end{array}$ & 42 & 70 \\
\hline The house should not assimilate traditional Emirati house & 5 & 8.3 \\
\hline \multicolumn{3}{|l|}{ Opinion about use of traditional architectural vocabularies } \\
\hline $\begin{array}{l}\text { House elevation and fenestration should be affected by traditional } \\
\text { architecture }\end{array}$ & 9 & 15 \\
\hline $\begin{array}{l}\text { House elevation and fenestration should have some link with } \\
\text { traditional architecture }\end{array}$ & 39 & 65 \\
\hline $\begin{array}{l}\text { House elevation and fenestration should not be affected by } \\
\text { traditional architecture }\end{array}$ & 12 & 20 \\
\hline
\end{tabular}


guests' zone, i.e. away from dining halls. In the male guests' zones the dining hall, with its own services, is in a strong connection with the majlis. For the family zone, except in Type D (Fig. 4), dining is taking place at the same sitting area without physical separation or allocation of specific dining areas. Therefore, the design is working in harmony with the preferences of most of the interviewed residents (Table 2).

The fourth indicator is the continuous manifestation of the indigenous Emirati art and architecture in the house design. Actually, it cannot be claimed that the architectural treatments and motives in the elevations of the investigated house models are derived from the traditional local architecture in the UAE (Fig. 7), rather it might be claimed to be derived, in an elective manner, from Arab/Islamic traditional cities. For example, the architectural style in Type D is apparently derived from Andalusian architecture (Fig. 4). Despite that, the majority of the interviewed families felt that the architectural styles of their houses either assimilate the traditional Emirati house in many facets $(30 \%)$ or in some aspects $(61.7 \%)$ (Table 4$)$. At the same time, $65 \%$ of them believed that the house elevation and its fenestration should have some link with the traditional Emirati house in some details but, also, the spirit of modernity needs to be reflected in them (Table 4).

The fifth investigated indicator was the 'preservation of the functional design heritage of the house' not in terms of the architectural expression but in terms of the traditional functions and their patterns of spatial organization. Actually, the pattern of the functional design of four out of the five investigated house models (all except Type B), reveals some sort of continuity with the traditional spatial organization where the inner court and introverted spaces were the norm. The majority of the interviewed families (70\%) claimed that the house should assimilate traditional Emirati houses in only some of the functions and spatial organization that have continuity in our era. The above analysis revealed that the second principle, the 'Responsiveness to cultural values', has been found to be 'Largely Achieved' (Fig. 8).

\subsection{Quality of life}

Measuring the principle of the 'quality of life' was undertaken through two indicators: the 'healthy indoor environment' and the 'good sense of place'. Each of these indicators was represented in some relevant variables as shown in Table 1. In terms of design, it was obvious that the main concern was given to having a repetitive house model rather than optimizing natural ventilation through having

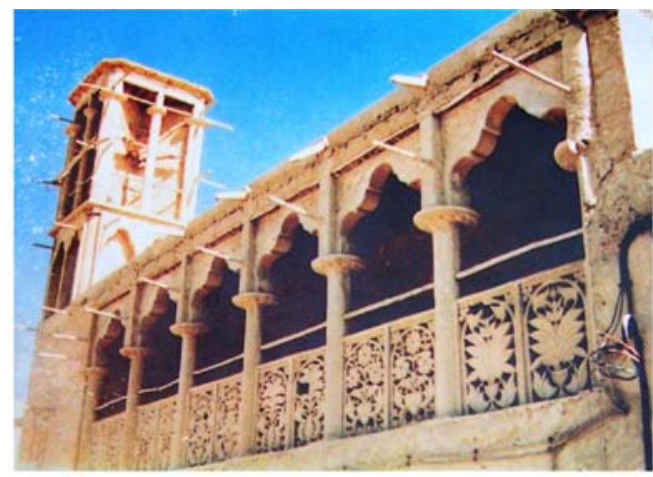

a)

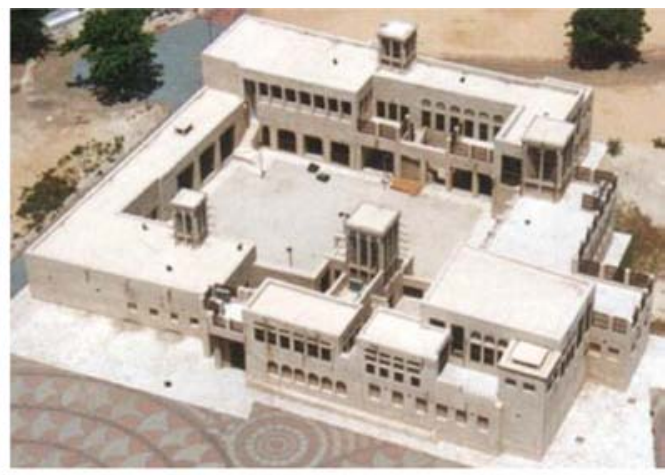

b)

Figure 7: Traditional houses in Dubai, UAE ([14] and www.dubaihistoric.ae). 


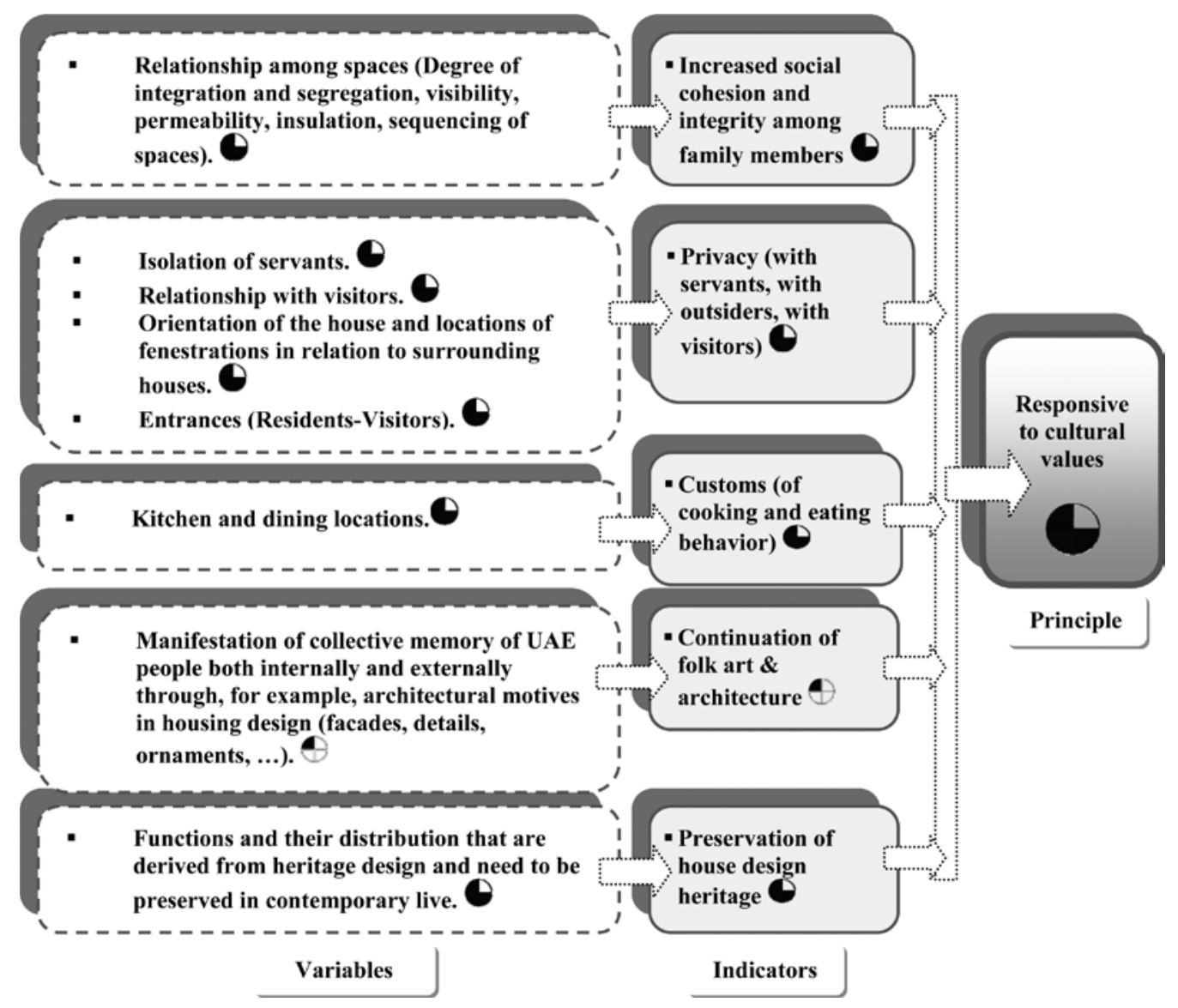

Figure 8: Evaluation of the second principle, 'Responsiveness to cultural values'.

an appropriate orientation for each individual house. Natural lighting was better due to the fragmentation of the mass of the house models (except Type B) into three separated masses. This also, albeit arbitrary, helped in creating cross-ventilation inside the internal spaces of the house. Mitigating the effect of solar radiation and direct heat gain was given little concern as it was dealt with through some sunshades and projected frames around windows (Figs 1,2, 4 and 5). The majority of the interviewed families thought that their houses enjoy good natural lighting and ventilation $(61.7 \%)$ or moderate natural lighting and ventilation (31.7\%) (Table 5). Mitigation of noise and air pollution (from surrounding streets) was left to residents to deal with. Many of the residents heavily planted local trees (Ghaph) and palm trees around their plots in a way that not only helped in providing privacy but also reduced the negative effects of vehicles pollution and noise. The majority of the interviewed families $(60 \%)$ believed that the design of their houses does not provide enough protection from the outside noise and pollution (Table 5).

For the second indicator, 'the good sense of place' and its measurable variables, the design analysis illustrated high degree of ease of movement inside each of the activity zones of the houses of both Types A and D followed by Types C, E and B. Nonetheless, in Types A and D the circulation among these separated activity zones was not that easy as it necessitates going outside one building and 
Table 5: Results of the interviewees' responses to the variables of the indicators of the third principle.

\begin{tabular}{lcc}
\hline Variable (Questions) & Frequency & Percent (\%) \\
\hline Natural lighting and ventilation & & \\
House design provides good natural lighting and ventilation & 37 & 61.7 \\
House design provides only some natural lighting and ventilation & 19 & 31.7 \\
House design does not provide natural lighting and ventilation & 4 & 6.7 \\
Noise protection & 12 & 20 \\
Outside noise reaches inside house & 36 & 60 \\
Outside noise reaches inside the house to some extent & 12 & 20 \\
Outside noise does not reach inside house & & \\
Ease of movement inside the house & 35 & 58.3 \\
House design allows for ease of movement inside it & 25 & 41.7 \\
House design allows for ease of movement inside it to some extent & & \\
Good view & 27 & 45 \\
House windows provide good views & 19 & 31.7 \\
House windows provide some good views & 14 & 23.3 \\
House windows do not provide good views &
\end{tabular}

getting inside another one thus moving between high temperature variations especially in summer where all the internal spaces are air conditioned and the weather outside is extremely hot. Meanwhile, $58.33 \%$ of the respondents believed that the house design allows for ease of movement inside it while a considerable percentage of them (41.67\%) thought that it partially allows for that.

Reviewing the details of the working drawings of the five investigated house models showed that windows were provided by screens to help protecting against insects. Also, when they were asked about the view that they enjoy from within their houses, $45 \%$ of the interviewed families mentioned that the windows of their houses provide good views and $31.7 \%$ of them mentioned that only some good views can be seen from their windows, while $23.3 \%$ of them pointed out that these windows provide no good views (Table 5). These results indicate that the issue of providing good views from inside the house was not highly raised when undertaking the design of the housing models. In conclusion, the above results indicate partial achievement of the third principle, the 'quality of life', in the design of the tested house models (Fig. 9).

\subsection{Adaptability}

For the fourth principle of the 'Adaptability' of the house design, two indicators were proposed. First is the 'responsiveness to individual preferences concerning allocated functions and areas of internal spaces'. And second is the 'ability for changing functions/areas of internal spaces' (Table 1). Actually, the ample vacant space of the house plot allowed for increasing the areas and adding new functions to the existing house in response to the new emerging familial needs. In their responses to relevant questions about house adaptability, the majority of the respondents mentioned that the design either allowed for change in functions and/or areas of the house rooms and halls (45\%) or it allowed for only partial changes in these predefined functions and/or areas (45\%) (Table 6).

It was found that the majority of the interviewed families (80\%) conducted changes in areas and/or functions of the spaces of their houses (Table 6). Most of the changes were represented in increasing the number of bedrooms, converting majlis into bedrooms and building a new majlis in the house 


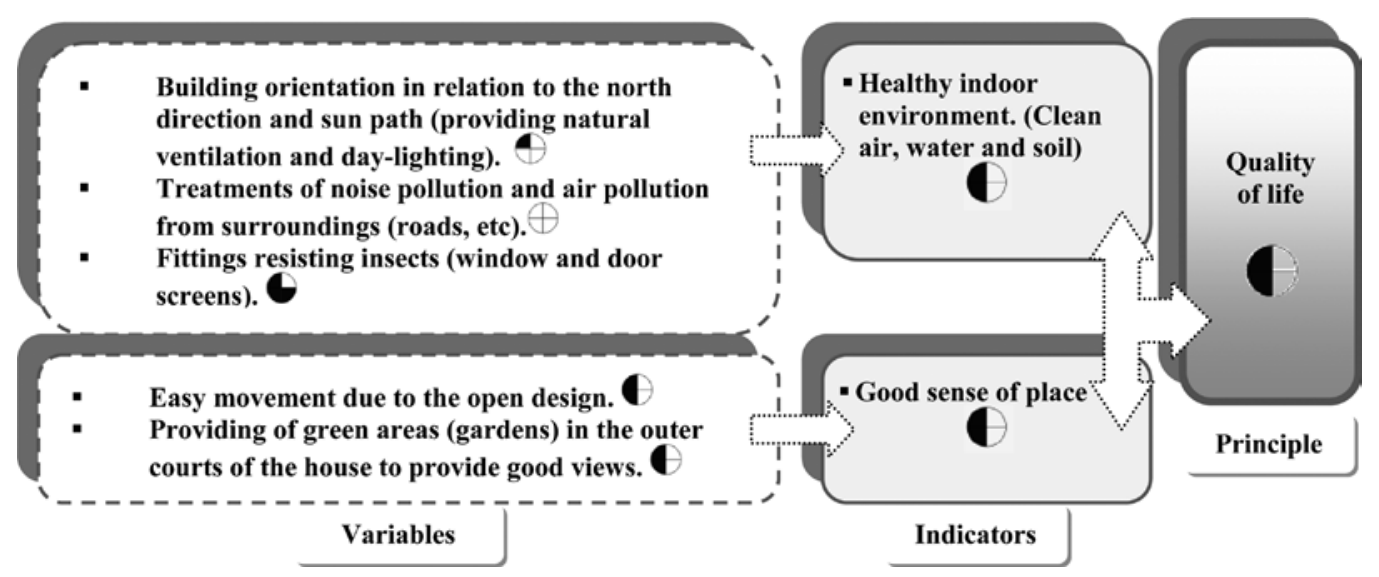

Figure 9: Evaluation of the third principle, 'quality of life'.

Table 6: Results of the interviewees' responses to the variables (questions) of the indicators of the fourth principle.

\begin{tabular}{lcc}
\hline Variable (Questions) & Frequency & Percent (\%) \\
\hline $\begin{array}{l}\text { Design adaptability } \\
\text { House design allows for change in function and/or areas of rooms }\end{array}$ & 27 & 45 \\
$\begin{array}{l}\text { House design only allows for some change in function and/or areas } \\
\text { of rooms }\end{array}$ & 27 & 45 \\
$\begin{array}{l}\text { House design does not allow for change in function and/or areas } \\
\text { of rooms }\end{array}$ & 6 & 10 \\
$\begin{array}{l}\text { Conducting change in functions and/or areas of rooms } \\
\text { Yes }\end{array}$ & 48 & 80 \\
No, we did not need any change in function and/or areas & 12 & 20 \\
\hline
\end{tabular}

plot. Figure 10 shows a lot of modifications undertaken by the residents in one of the original house models (Type D) in Neima district. This indicates that the designs of the investigated house models can be considered adaptable to a large extent and hence the principle of 'Adaptability' can be considered 'Largely Achieved' (Fig. 11).

\subsection{Safety}

For the principle of 'Safety' one indicator was selected, the 'protection from hazards'. The review of the working drawings and design details of the five investigated models revealed that there are no real safety measures that were considered in the design process. The majority of the interviewed families $(78.3 \%)$ pointed out that their houses are not provided with any means for fire protection. And almost half of the interviewed families (55\%) mentioned that the floorings of their houses might cause slipping (Table 7). These results show that 'Safety', as a principle, has been 'Limitedly Achieved' (Fig. 12). 


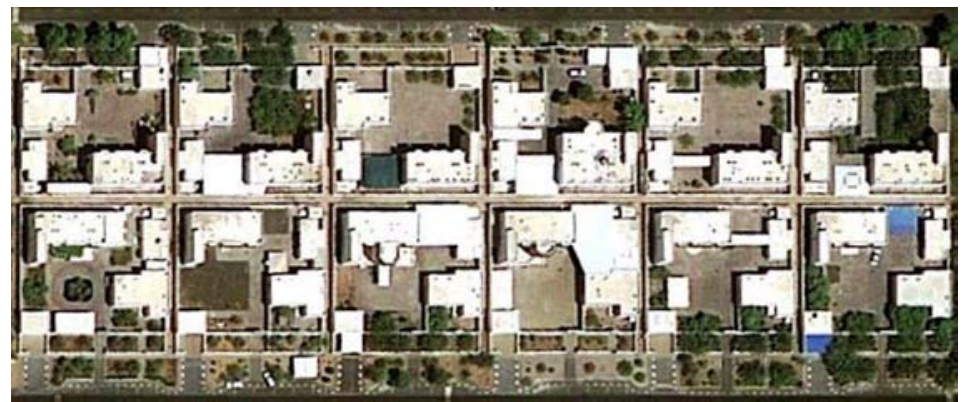

Figure 10: Modifications and extensions of Type D house model undertaken by the residents in Neima district in Al Ain [Source: Google Earth, September 2009].

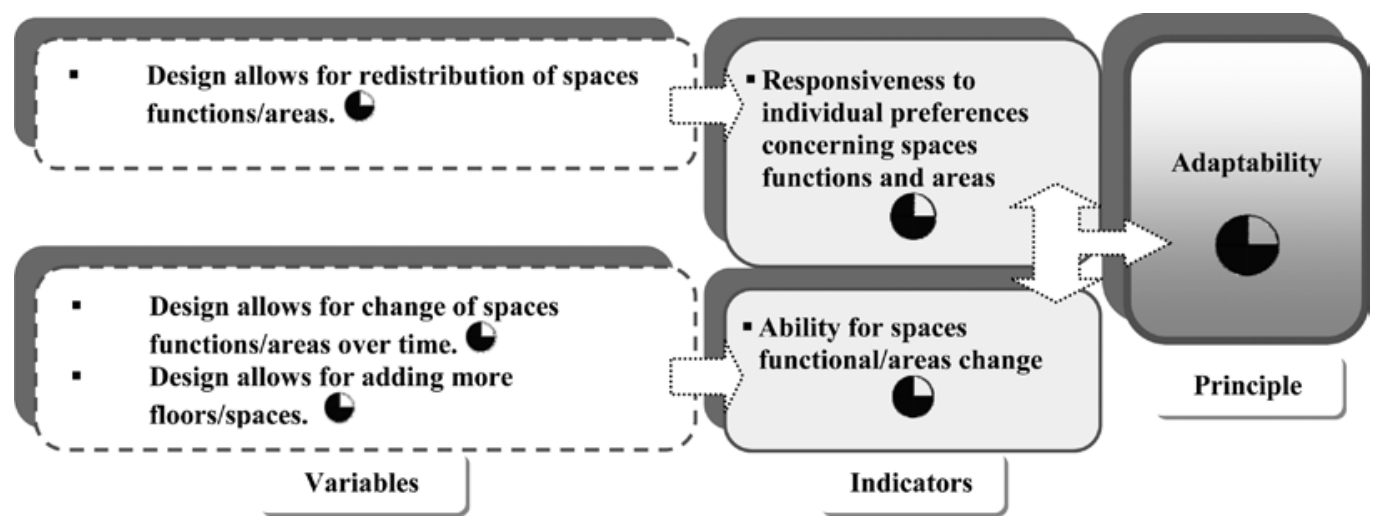

Figure 11: Evaluation of the fourth principle, 'Adaptability'.

Table 7: Results of the interviewees' responses to the variables (questions) of the indicator of the fifth principle.

\begin{tabular}{lcc}
\hline Variable (Questions) & Frequency & Percent (\%) \\
\hline Fire protection & & \\
House is equipped with means of fire protection & 13 & 21.7 \\
Means of fire fighting are rare or not found & 47 & 78.3 \\
House floorings & & 45 \\
House floorings are anti-slipping & 27 & 55 \\
House floorings might cause slipping & 33 &
\end{tabular}

\subsection{Security}

'Security' is the sixth principle for socio-cultural sustainability in the house design. 'Protection from crimes' is the selected indicator for this principle. Three variables were proposed for assessing this indicator (Table 1). In terms of the provision for security measures, the analysis of the design 


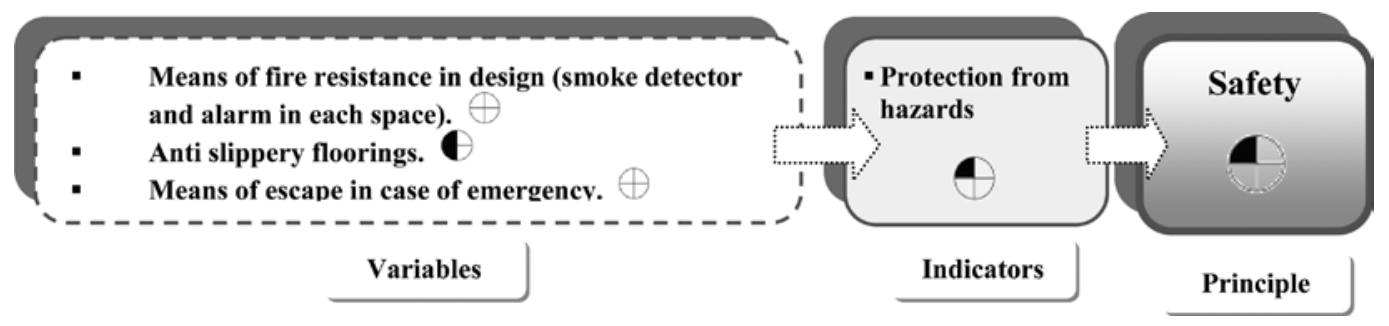

Figure 12: Evaluation of the fifth principle, 'Safety'.

revealed that, first, all the house models have high and opaque peripheral fences and gates that aimed at providing both security and privacy for the households. Second, the analysis of the locations of the internal spaces showed that the main lobbies and corridors in all of the five investigated house models are enjoying high visual control over the internal functional spaces. Also, the locations of the family living halls enabled for high visual control over the outdoor spaces of the house plot. On the other hand, the majority of the interviewed families (83.3\%) mentioned that they feel that the fences and gates of their houses provide a good sense of security for them (Table 8). Less, but still considerable majority of the interviewed families $(61.7 \%)$, felt that the fenestrations in their houses are designed in a way that provides security for them. In addition, a considerable number or the interviewed families (56\%) mentioned that they need additional means of security in their houses (Table 8). These results indicate that the principle of 'Security' has been 'Partially Achieved' (Fig. 13).

\subsection{Participation}

The indicator selected for the seventh principle of 'Participation' is the inhabitants' 'involvement in the decision-making processes' pertaining to their houses. According to the UAE government regulations the citizens usually apply for a new public house in a specific city even before the development of the housing project. The relevant measured variables included the residents' participation in the selection of the site of the house plot and its total area as well as their participation in the design of the house itself. As expected, the majority of the interviewed families (80\%) had no chance to participate in the selection of the locations of their houses (Table 9). Even higher percentage of the interviewed families (93.3\%) had no chance to take part in the selection of the areas of their houses. On the architectural design level, only $26.7 \%$ of the interviewed families had the chance to select the design models of their houses (Table 9). This makes this principle 'Limitedly Achieved' (Fig. 14).

\subsection{Accessibility (inclusive/universal design)}

'Accessibility' or inclusive/universal design is the eighth principle for socio-cultural sustainability in houses. Two indicators were used for evaluating this principle. First is the 'appropriate measures for elderly residents' and second is the 'appropriate measures for handicapped and children residents'. The analysis of the design details of the five house models revealed that the main accesses for family zones are not accessible by elderly or handicapped residents expect for Type A which has a flat access (Fig. 1). The main staircases in the two story houses (Types A, B, D and E) are not equipped or even suitable for being equipped with means for convenient vertical circulation for elderly or handicapped inhabitants, such as stair elevators. 
Table 8: Results of the interviewees' responses to the variables (questions) of the indicator of the sixth principle.

\begin{tabular}{lcc}
\hline Variable (Questions) & Frequency & Percent \\
\hline House fences and gates & 50 & \\
House fences and gates provide required sense of security & 10 & 16.7 \\
House fences and gates are not satisfying security requirements & & \\
Fenestration design & 37 & 61.7 \\
Fenestrations are designed in a way that provide security & 23 & 38.3 \\
Fenestrations are not properly designed for providing security & & \\
Need for additional means of security in the house & 33 & 55 \\
Yes & 27 & 45 \\
No & &
\end{tabular}

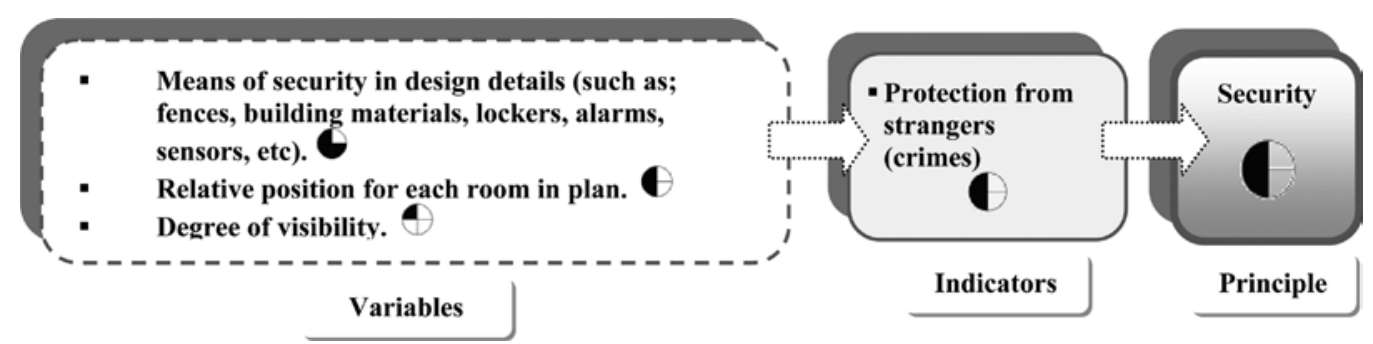

Figure 13: Evaluation of the sixth principle, 'Security'.

Table 9: Results of the interviewees' responses to the variables (questions) of the indicator of the seventh principle.

\begin{tabular}{lcc}
\hline Variable (Questions) & Frequency & Percent \\
\hline Participation in house site selection & 12 & 20 \\
Yes & 48 & 80 \\
No & & \\
Participation in house area selection & 4 & 6.7 \\
Yes & 56 & 93 \\
No & & \\
Participation in house architectural design & 16 & 26.7 \\
Yes & 44 & 73.3 \\
No & & \\
\hline
\end{tabular}




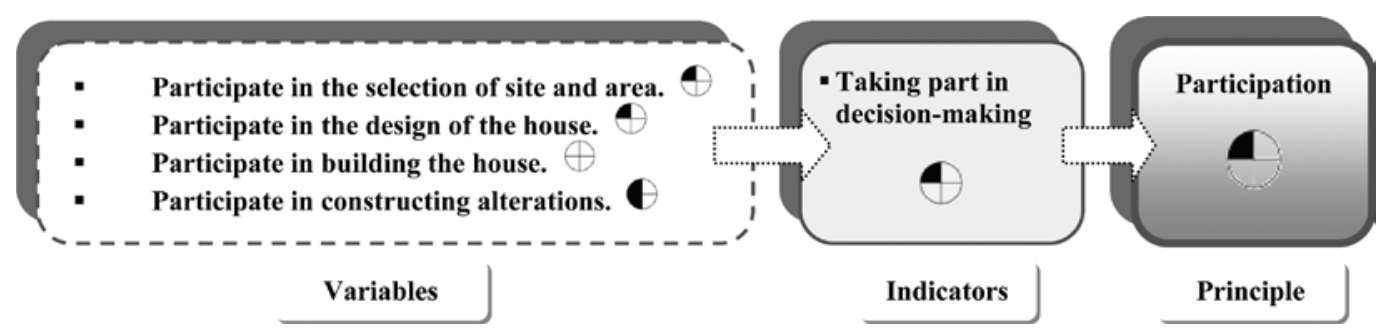

Figure 14: Evaluation of the seventh principle, 'Participation'.

$61.7 \%$ of the interviewed families pointed out that the elderly residents suffer $(6.7 \%)$ or suffer to some extent (55\%) from using lofted entrance staircases and internal staircases (Table 9). In addition, the majority of the interviewed families (76.7\%) mentioned that there is no lofted threshold on the doors of bedrooms and bathrooms so this makes these spaces easily accessible by elderly, handicapped and children, if any.

In the design of the five investigated house models, the widths of the corridors and doors were found to be more than $120 \mathrm{~cm}$ for the former and $90 \mathrm{~cm}$ for the later. Thus, they are suitable for the use by persons in wheelchairs. The great majority of the interviewed families (96.7\%) agreed that the locations of the knobs and lockers of the doors and windows as well as the locations of the light switches at their houses are suitable for everyone in the family including children, elderly people and handicapped, if any. In addition, the majority of the interviewed families (83.3\%) agreed that the garage is suitably located in the house plot as it leads directly to the house entrance. Both the design analysis and the majority of the interviewed families (75\%) indicated that the area allocated for the car parking is wide enough to allow for accessibility from, and to, the family car for all family members including elderly and handicapped, if any (Table 10). So, based on the above results it could be claimed that the principle of 'Accessibility' is found to be 'Largely Achieved' (Fig. 15).

To conclude, the research multiple investigations using the two main tools, the design analysis of the five selected public houses models and the face-to-face structured interviews with a sample of the Emirati families living in these selected house models, have revealed that four out of the eight principles of the socio-cultural sustainability in houses have been significantly achieved. These principles are: 'Responsiveness to social needs', 'Responsiveness to cultural needs', 'Adaptability' and 'Accessibility'. Two other principles have been found to be partially achieved: the 'Quality of life' and 'Security'. The two remaining principles, namely, 'Safety' and 'Participation' have been found to be 'Poorly Achieved'.

\section{PROPOSED DESIGN GUIDELINES FOR ACHIEVING SOCIO-CULTURAL SUSTAINABILITY IN PUBLIC HOUSES IN AL AIN}

Based on the above findings and in order to fulfill its second objective, the research is proposing, not full architectural rigid designs but rather, some design guidelines for achieving socio-culturally sustainable public houses in $\mathrm{Al}$ Ain, and in UAE in general. These guidelines are subsumed into eight main categories representing the eight socio-cultural sustainability principles in houses.

First, achieving 'Responsiveness to social needs' simply means satisfying all the needed functional spaces. Given the difficulty of this target, especially for the required number of bedrooms, it seems that the idea of having an expandable house (such as in the case of Types A and E) sounds applicable and practical. The house, thus, can begin with four or five bedrooms and then the residents are allowed to incrementally increase this number, if and when needed, either horizontally or vertically 
Table 10: Results of the interviewees' responses to the variables (questions) of the indicators of the eighth principle.

\begin{tabular}{lcc}
\hline Variable (Questions) & Frequency & Percent \\
\hline Elevated house entry with a staircase & 33 & 55 \\
Yes & 27 & 45 \\
No & 4 & 6.7 \\
Elderly suffers from using staircases & 33 & 55 \\
Yes & 23 & 38.3 \\
To some extent & & \\
No & 14 & 23.3 \\
Threshold on rooms and bathrooms entries & 46 & 76.7 \\
Elevated & & \\
At the same level & 58 & 3.3 \\
Locations of doors and windows knobs and light switches & 2 & 83.3 \\
In a suitable height for everyone & & 16.7 \\
Some household find difficulty in reaching them & 50 & 75 \\
Location of car parking & 10 & 25 \\
Leads directly to house entrance & & \\
Away from house entrance & 45 & \\
Area of car parking & 15 & \\
Suitable for household needs and ease of riding & & \\
Not sufficient for household needs and ease of riding & & \\
\hline
\end{tabular}

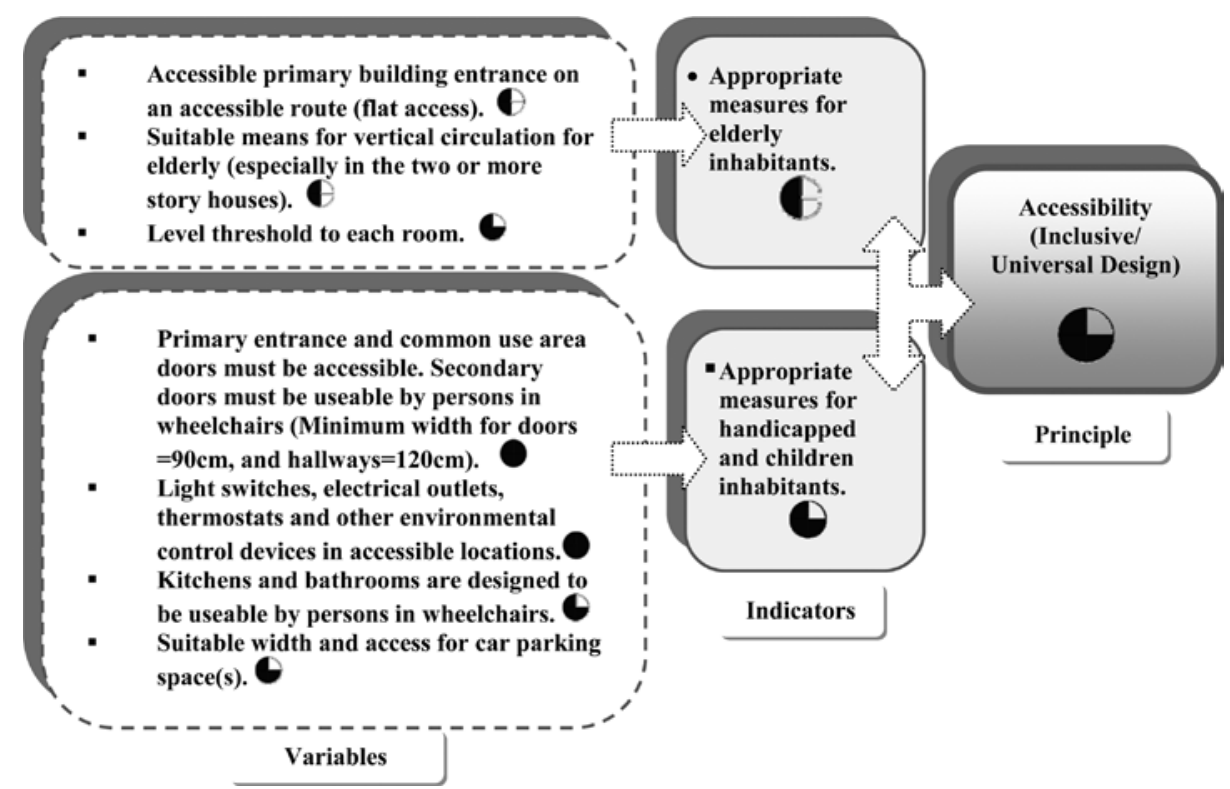

Figure 15: Evaluation of the eighth principle, 'Accessibility (inclusive/universal design)'. 
under the permission and supervision of the municipality. Concerning the suitable number of service facilities, the current rate of having a bathroom for each two bedrooms, 1 bathroom for the master bedroom, 1 toilet and hand-wash basins for serving male guests with similar numbers for serving the family hall, 1 main kitchen, a maid's room and a driver's room with toilets and finally a store seems generally suitable in terms of numbers. Nonetheless, with the idea of expansion, increasing the number of facilities might need to be considered. In addition, each house should have a garden as this has proved to be an essential need for the Emirati residents. While the design should encompasses terraces and balconies it should, at the same time, allow the residents to modify them to be part of the internal spaces if they want so. Current areas for the family living hall, the majlis hall and the dining hall (about $4 \mathrm{~m} \times 6 \mathrm{~m}$ ) should be increased to suit the social events and guests gatherings as this is an essential social custom of the Emirati society. On the other hand, the separation of the male guests zone which encompasses the majlis hall and the dining hall as well as the separation of the service facilities zone, to some extent, from the family zone sound desirable. So the compactness of the main three zones (family, male guests and services) should be avoided or at least dealt with in a way that create some actual isolation especially between the male guests zone and the family zone and also to create some, even less, isolation between family zone and service zone (Fig. 16). Finally, a design for two floors house or one floor that can be expanded to two is recommended.

Second, for achieving 'Responsiveness to cultural values', social cohesion and integrity among family members should be intensified through achieving more integration and visibility among the internal spaces in the family zone by avoiding, for example, single or double loaded long corridors. Furthermore, the house design should provide privacy with its residents on multiple levels. First, there should be privacy for family members as well as guests and servants from outsiders. This can be achieved through careful orientation of the house masse(s) in relation to its surroundings, careful design of external fences, careful design of landscape elements such as trees and appropriate technical treatment for windows especially in the upper floors, such as using mirrored glazing, to prevent visual corridors from outside. Second is the privacy for family members from male guests. This can be achieved through careful positioning of doors and windows of the three separated activities zones in the house and also by separating entrances for guests and family members. Regarding the local customs of cooking and eating behavior, the main kitchen should be positioned outside the main family zone but, at the same time, it should be easily accessible from it. Other small family kitchenette should be provided in the family hall to serve family members easily for quick snacks and drinks. In order to work towards preserving the indigenous Emirati art and architecture, the author believes that the house design needs to reflect the collective memory of the UAE people both internally and externally through the utilization of modernly reformed, rather than cut-and-pasted, traditional architectural vocabularies and motives that can be manifested in the house facades, details of windows, doors and internal ornaments. On the other hand, for preserving the functions of the traditional Emirati houses, the house design should keep such functions especially the majlis and dining halls for male guests and also an inner court/lobby surrounded by the three house zones (Fig. 16).

Third, achieving a good 'Quality of life' necessitates creating a healthy indoor environment by providing good day lighting and natural ventilation through appropriate building orientation in relation to the north direction and sun path (Fig. 16). Sources of noise and air pollution from surroundings, such as main roads, should be treated in the house design through, for example, using well-sealed double glazing fenestrations and thermally and acoustically insolated building envelop. Achieving healthy indoor environment also necessitates providing windows and doors with fittings that can resist insects such as mesh screens and insect resisting plants. In order to keep a good sense of place among the inhabitants, house design should pay attention not only to the provision of green areas and gardens in the outer courts of the house, but also to having good landscape for them. Good sense 


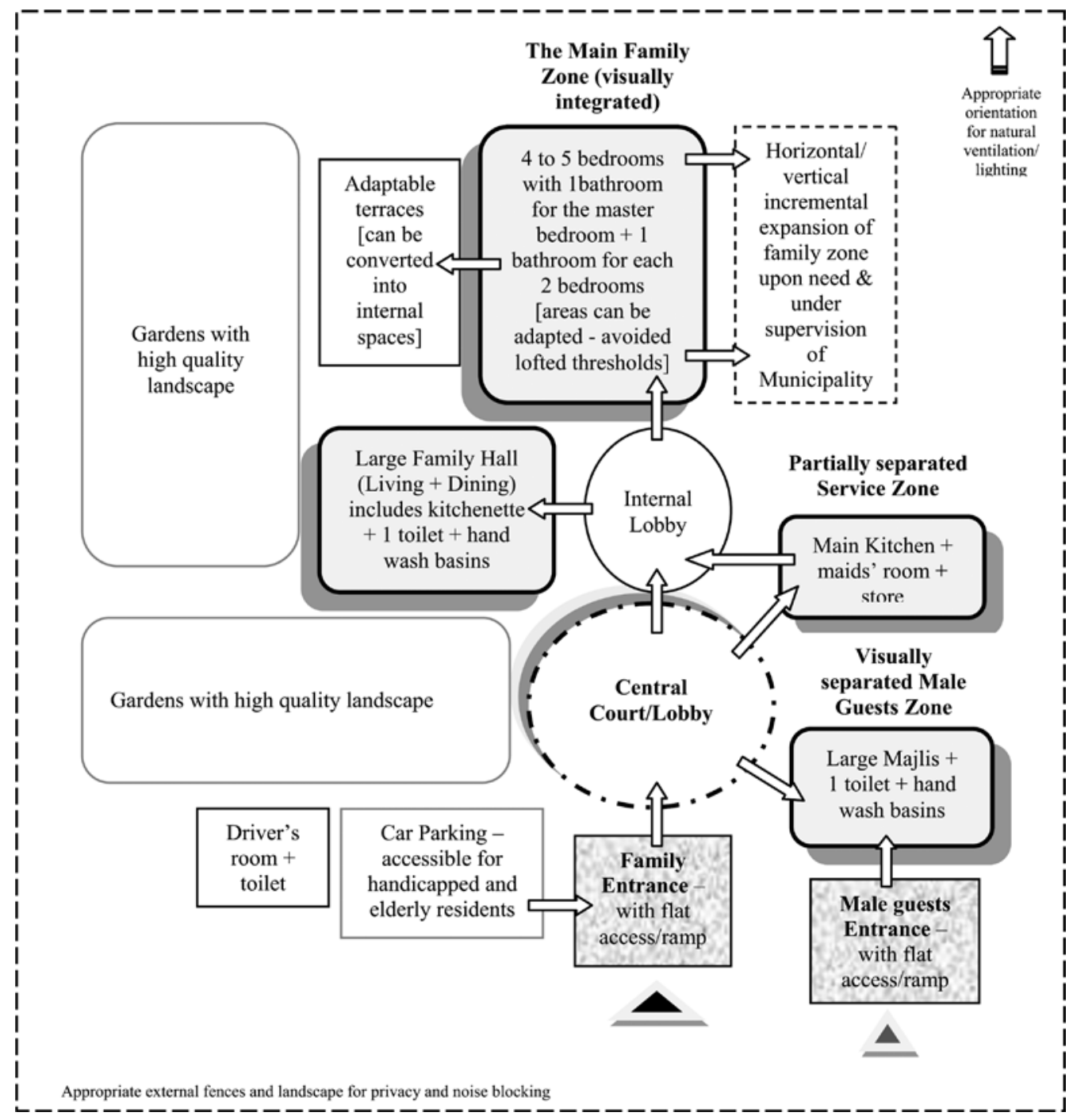

Figure 16: A diagram for the proposed public house design guidelines.

of place can also be intensified internally by considering ease of movement through adopting open design approach, when appropriate.

Fourth, achieving 'Adaptability' is an essential design concern. Over time and with the expected familial changing needs, there should be ability for changing functions/areas of the internal spaces. Therefore, the design of the house should allow accommodating these changes efficiently. The house model design has to be responsiveness to individual preferences of the families by allowing for the redistribution of the functions/areas of the internal house spaces based on the different familial preferences. This needs a good deal of flexibility on the part of the design and the structure system. For example, dropped beams between spaces should be avoided and movable partitions can be used instead of the fixed conventional masonry ones. 
Fifth, for achieving 'Safety' there should be a real protection from hazards. The house design should include suitable means of fire resistance such as fire rated doors especially in kitchens, smoke detectors and smoke alarms in each space. Anti slippery floorings, in both internal and external spaces, should be considered in the house detailed design. Escape in the case of emergency should be also studied in the design.

Sixth, in order to achieve 'Security' the house design should provide means for suitable protection from crimes. This includes a proper design for external fences, appropriate building materials, lockers, alarms and sensor lighting. Rooms and halls should be positioned in a way that allows for effective visual control. The design should also provide a good degree of visibility from within the house to the outside courts of the house plot.

Seventh, for 'Participation' to be achieved it needs genuine residents' involvement in the whole decision making processes relevant to their houses. This includes their participation in the selection of the site and the area of the house plot, in the design and building of their houses and in conducting extensions and/or alterations of the internal functional spaces. Participation in the design of the house can be realized, albeit not ideally, through giving the inhabitants the ability to select among design alternatives that are all adaptable and responsive to future inevitable changes.

Eighth, achieving 'Accessibility' or inclusive design for elderly, children and handicapped persons, if any, in the family can be realized through design measures such as having flat access instead of, or in addition to, entrance staircases (Fig. 16), suitable means for vertical circulation for elderly without the need for a lift. Instead, stair elevators that require a specific design for the handrail and the shape of the staircase can cater for this measure. Lofted threshold in each room and bathrooms should also be avoided. For the doors to be useable by persons in wheelchairs the minimum width should be larger or equal to $90 \mathrm{~cm}$, and for hallways should be larger or equal to $120 \mathrm{~cm}$. Light switches, electrical outlets, thermostats and other environmental control devices should be designed to be in accessible locations for them and for children. Finally, car parking should be designed according to appropriate width and access for elderly and wheelchair users.

\section{CONCLUSIONS}

Of the three pillars of sustainable development, social sustainability is perhaps the least explored within the mainstream development literature. Initially, the intellectual debate on this relatively new paradigm was mainly confined to two of its basic dimensions: economic sustainability and environmental sustainability. The current commitment of the UAE government towards adopting sustainability in the building sector including the housing initiated a lot of initiatives addressing the issue including this research. The main concern of the research is to go beyond the environmental aspects of sustainability and to address the social and cultural considerations of it in the typical design models of the public houses adopted by The Sheikh Zayed Housing Program. As many public housing projects have been constructed in Al Ain, a city intensively occupied by Emirati citizens, five housing models prevailed in the city were selected as the scope for this qualitative research with its multi-facets analytical tools including first the professional analysis where the researcher, as an architect, analyzed the architectural designs of these models, and second the face-to-face structured questionnaires with a sample of the occupants of the selected case studies.

Through an in-depth qualitative analysis the research defined and then evaluated eight main principles for socio-cultural sustainability relevant to the public houses in $\mathrm{Al}$ Ain as follows: responsiveness to social needs, responsive to cultural values, quality of life, adaptability, safety, security, participation, and accessibility (inclusive/universal design). The definition of these principles was mainly based on both 'global' literature review and the 'localized' outcomes of the focus 
group sessions conducted with some Emirati residents. Then, some relevant indicators with their measurable variables were tailored for each of these principles.

As a result for the research analysis a clearer understanding of the actual considerations of social and cultural sustainability in the designs of the public single family houses in Al Ain, and actually in most of the UAE cities, was realized fulfilling the first objective of the research. The research multiple investigations have revealed that four out of the eight principles of the socio-cultural sustainability in houses have been significantly achieved. These principles are: 'Responsiveness to social needs', 'Responsiveness to cultural needs', 'Adaptability' and 'Accessibility'. Two other principles have been found to be partially achieved: the 'Quality of life' and 'Security'. The two remaining principles, namely, 'Safety' and 'Participation' have been found to be poorly achieved. Based on these findings the research, in order to achieve its second objective, has proposed some design guidelines in order to help achieving socio-culturally sustainable public houses in Al Ain, and in UAE in general. This proposed design guidelines are subsumed into eight categories representing the main eight socio-cultural sustainability principles and are tailored in a way that is envisaged to bridge the gaps found through the research investigations especially for the partially and poorly achieved principles.

\section{ACKNOWLEDGMENTS}

The researcher would like to express his sincere appreciation to the Research Affairs at the United Arab Emirates University for the financial support for this project under fund grant \# 01-03-7-11/08. The investigator would also like to acknowledge the support of Al Ain Municipality and the influential contribution of the students of the Architectural Engineering Department at the UAE University.

\section{REFERENCES}

[1] Lewis, D.C. \& Kitchens, S.C., A Sustainable House for the Southeastern United States, Southern Climatic Housing (SCH) Report 5, Mississippi State University: USA, 2006.

[2] McKenzie, S., Social Sustainability: Towards Some Definitions, Working Paper Series No 27, Hawke Research Institute, University of South Australia: Australia, 2004.

[3] Brisbane Institute, Social Sustainability: The Missing Dimension, Brisbane Institute: Queensland, 2006.

[4] Mohammad, F. \& Amato, A., Public housing and social sustainability indicators: HK-BEAM as a case study. Proc. of the Annual Research Conference of the Royal Institution of Chartered Surveyors, COBRA, University College London: London, 2006.

[5] Barron, L. \& Gauntlett, E., WACOSS Housing and Sustainable Communities Indicators Project. Stage 1 Report - Model of Social Sustainability. Available online: http://www.wacoss.org. au/index.php?option=displaypage \&Itemid=421\&op=page, 2002.

[6] European Sustainable Trade Forum, Management of Sustainability, http://www.gdrc.org

[7] Chiu, R.L., Socio-cultural sustainability of housing: a conceptual exploration, Housing Theory and Society, 21, pp. 65-76, 2004. doi:10.1080/14036090410014999

[8] Barnett, K. \& Buys L., Tenants' Evaluation of Experiences of Social Sustainability within the Home Environment, Final Report, Department of Public Works and the Department of Housing (Queensland), Queensland University of Technology (QUT), and Centre for Social Change Research (CSCR): Australia, 2005.

[9] Nessa, W., On indicators of sustainable housing in the European urban context. Proc. of the ENHR Conference, ENHR: Ljubljana, 2006.

[10] Buys, L., Barnett, K., Miller, E. \& Bailey, C., Smart housing and social sustainability: learning from the residents of Queensland's research house, Australian Journal of Emerging Technologies and Society, 3(1), pp. 43-57, 2005. 
[11] Fletcher, V., Designing for life: inclusive residential design for socially sustainable communities. Proc. of the Housing Washington 2008 Symposium, Institute for Human Centered Design: Washington, 2008.

[12] Al Ain Municipality, Unpublished Architectural Drawings and Reports of Public Housing Projects, Al Ain Municipality: Al Ain, 2010.

[13] Galal Ahmed, K., Achieving socio-cultural sustainability in the design of the Governmentsponsored single family houses in the UAE: the case of Al Ain. Proc. of the Sustainable City 2010, the Sixth International Conference on Urban Regeneration and Sustainability, WIT: UK, 2010.

[14] Al-Abdouly, K.G., Development of Architectural Direction in UAE, Al-Ithad: Abu Dhabi, 1989. 